\title{
Sn-based catalysts for Baeyer-Villiger oxidations by using hydrogen peroxide as oxidant
}

\author{
Xiangzhi Cui and Jianlin Shi*
}

\begin{abstract}
Baeyer-Villiger (BV) oxidation is one of the most important transformation reactions in synthetic organic chemistry. Catalytic versions of the $\mathrm{BV}$ oxidation are particularly attractive in practical applications, because the catalytic transformation substantially simplifies reaction process while minimizing reactant consumption as well as waste production. Further benefits are expected from replacing peracids, the traditionally used oxidant, by low cost and environmentally friendly hydrogen peroxide $\left(\mathrm{H}_{2} \mathrm{O}_{2}\right)$. This review will first introduce very briefly the features of $\mathrm{BV}$ oxidation reactions, and the corresponding oxidants traditionally used. Afterwards, the emphasis will be placed on the specific Sn-based catalysts, their performance comparison for the $\mathrm{BV}$ oxidation reaction by using $\mathrm{H}_{2} \mathrm{O}_{2}$ as oxidant, and the catalytic mechanisms of most $\mathrm{Sn}$-based catalysts reported so far, including homogeneous Sn-based catalysts (such as Sn-based fluorous biphase system catalysts), heterogeneous $\mathrm{Sn}$-based catalysts (such as Sn-based zeolite catalysts, $\mathrm{Sn}$-based mesoporous composites, Sn-incorporated clay catalysts, Sn-based metal oxide composites and polymer supported Sn catalysts). Finally, the $S n$-based catalysts for BV oxidation are outlooked for their potentials and perspectives in enhancing the performance and then accelerating the practical applications of $\mathrm{BV}$ oxidations by using $\mathrm{H}_{2} \mathrm{O}_{2}$. The developing direction of the $\mathrm{Sn}$-based catalytic $\mathrm{BV}$ reaction is also illustrated.
\end{abstract}

Keywords: Baeyer-Villiger oxidation, tin based catalyst, catalysis

\section{INTRODUCTION}

The BV oxidation (also called Baeyer-Villiger rearrangement), named after Adolf Baeyer and Victor Villiger who first reported the reaction in 1899 , is an organic reaction that forms an ester from a ketone as shown in Scheme 1, or a lactone from a cyclic ketone by using peroxyacids or peroxides as the oxidant $[1,2]$. Since valuable lactones or esters can be obtained directly from the corresponding ketones, BV oxidation has become one of the most important transformations in organic synthesis [3-6]. Generally, percarboxylic acids (i.e., meta-chloroperbenzoic acid $(m$-CPBA), peracetic acid, etc.) are the most common and suitable oxidants used in BV oxidation, but they are becoming problematic for industrial scale use due to their generating amounts of carboxylic acid waste as side product and resulting in low ester selectivity [7-9] . Moreover, percarboxylic acids are expensive, and unstable in solution and typically require chlorinated solvents for improved performance [10]. In contrast, hydrogen peroxide $\left(\mathrm{H}_{2} \mathrm{O}_{2}\right)$ is environmentally friendly and generates water as the only co-product of its reduction, which can avoid many of the problems associated with peroxy carboxylic acids as oxidants [11]. On the other hand, $\mathrm{H}_{2} \mathrm{O}_{2}$ is also commercially available, low cost, and easy to handle. In addition, $\mathrm{H}_{2} \mathrm{O}_{2}$ contains a higher concentration of active oxygen ( $47 \mathrm{wt} . \%$ ) than all other oxidants except molecular oxygen, which not

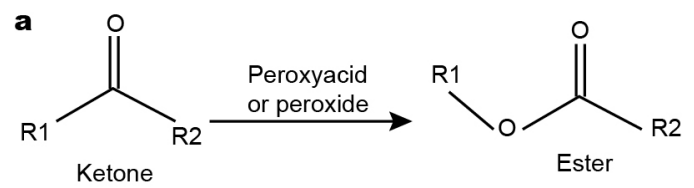

b
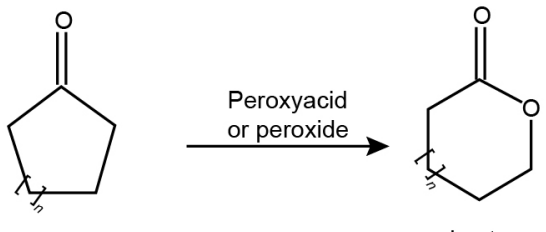

Cyclic ketone

Lactone

Scheme 1 General BV oxidations of (a) a ketone to an ester and (b) a cyclic ketone to a lactone.

State Key Laboratory of High Performance Ceramics and Superfine Microstructures, Shanghai Institute of Ceramics Chinese Academy of Sciences, Shanghai 200050, China

*Corresponding author (email: jlshi@mail.sic.ac.cn) 
only results in improved process economics but also leads to lower effluent outputs [12-14]. Therefore, attention is now focused on how to replace percarboxylic acids with aqueous hydrogen peroxide.

Thus, much research has focused on the development of effective catalysts for efficient $\mathrm{BV}$ oxidation using low cost $\mathrm{H}_{2} \mathrm{O}_{2}$ oxidants. Some successes have been achieved with homogeneous catalysts containing active centers based on Se [15], Re [16], Zr [17], W [18], Pd [19], Pt [20], Mn [21], or with solid acids $[22,23]$. All of these catalysts have at least one drawback, such as low activity or poor selectivity, tedious recovery and regeneration, or high costs for starting materials and/or safety precautions. Uyanik et al. [24,25] reported that the lipophilic $\mathrm{Li}\left[\mathrm{B}\left(\mathrm{C}_{6} \mathrm{~F}_{5}\right)_{4}\right]$ or $\mathrm{Ca}\left[\mathrm{B}\left(\mathrm{C}_{6} \mathrm{~F}_{5}\right)_{4}\right]$ catalyst show highly efficient and selective catalytic activity for BV oxidation of ketones with 30 wt.\% aqueous $\mathrm{H}_{2} \mathrm{O}_{2}$ to give a high yield lactones, which leads to a new development direction of $\mathrm{BV}$ catalysts. While the synthesis procedure of $\mathrm{Li}\left[\mathrm{B}\left(\mathrm{C}_{6} \mathrm{~F}_{5}\right)_{4}\right]$ or $\mathrm{Ca}\left[\mathrm{B}\left(\mathrm{C}_{6} \mathrm{~F}_{5}\right)_{4}\right]$ catalysts is complicated. ten Brink et al. [26] gave a comprehensive review about the new developments toward greener procedures during the $\mathrm{BV}$ oxidation by using $\mathrm{H}_{2} \mathrm{O}_{2}$ as green oxidants, and the development of cleaner reactions, such as nonchlorinated solvents, is still necessary, and they also pointed out that the better catalysts for the activation of hydrogen peroxide are still needed.

Tin (Sn) based catalysts, as one of the most important catalyst for the BV oxidation by using $\mathrm{H}_{2} \mathrm{O}_{2}$ as oxidant, are attracting extensive attention because of its cost-effect, special character of Lewis acid sites and the non-toxic characters, which exhibits excellent application prospect in the BV oxidation reaction. ten Brink et al. [26] also pointed out that the Sn-MCM-41 as solid Lewis acid catalysts are highly interesting for the large-scale BV oxidation reactions. Although several reviews on the BV reactions have been published, which covers the development of the BV oxidation, the concerned oxidants, corresponding catalysts, etc. $[27,28]$, no review aiming at the specific Sn-based catalysts for BV oxidation by using $\mathrm{H}_{2} \mathrm{O}_{2}$ as oxidant was published.

Since the Sn-based catalysts as a kind of transitional metal based composites are extensively researched for BV oxidation, the focus of this review is on the Sn-based catalysts for the BV oxidation by using $\mathrm{H}_{2} \mathrm{O}_{2}$ as oxidant. Firstly, the progresses in the development of Sn-based catalysts were reviewed, and the catalytic activity was compared and discussed; secondly, the mechanism of Sn-based catalysts was probed to better understand the catalytic BV oxidation process, and finally, a summary and outlook were provided to illustrate in which direction the Sn-based catalytic BV reaction is developing.

\section{Sn-BASED CATALYSTS FOR BV OXIDATIONS BY USING $\mathrm{H}_{2} \mathrm{O}_{2}$}

Sn-based catalysts, including homogeneous and heterogeneous catalysts, exhibit excellent catalytic activity for BV oxidation by using $\mathrm{H}_{2} \mathrm{O}_{2}$ because of their special Lewis acid characters, which will be reviewed and discussed in detail.

\section{Homogeneous Sn Catalysts}

One of the most important and significant progresses in the development of homogeneous Sn catalysts is the Sn-coordinated fluorous compounds used in the so-called fluorous biphase system (FBS), which was first introduced by Horváth and Rábai in 1994 [29] and has exhibited some potential advantages over the classical homogeneous catalysts, including easy and effective separation and recycling of the catalyst [30]. The new kind of tin(IV) bis(perfluorooctanesulfonyl)amide complex $\left(\mathrm{Sn}\left[\mathrm{N}\left(\mathrm{SO}_{2} \mathrm{C}_{8} \mathrm{~F}_{17}\right)_{2}\right]_{4}\right)$ is used as catalyst to realize the $\mathrm{BV}$ oxidation of several kinds of ketones in $\mathrm{FBS}$, and perfluoro(methylcyclohexane) $\left(\mathrm{CF}_{3} \mathrm{C}_{6} \mathrm{~F}_{11}\right)$ and 1,2-dichloroethane $\left(\left(\mathrm{CH}_{2}\right)_{2} \mathrm{Cl}_{2}\right)$ or 1,4-dioxane are used as solvent. The catalytic activity of Sn active center can be tuned by changing the ligand. As shown in Table 1, by using $-\mathrm{N}\left(\mathrm{SO}_{2} \mathrm{C}_{8} \mathrm{~F}_{17}\right)_{24}$ as ligand, the selectivity of ester reaches $97 \%-99 \%$, especially the conversion rates of BV oxidation of cyclobutanone and adamantanone can reach at $97 \%$ and $94 \%$, respectively, which is higher than that of those using $-\mathrm{OSO}_{2} \mathrm{CF}_{3}$ as ligand [31,32]. Compared to other homogeneous catalysts, the catalyst completely immobilized in the fluorous phase, and therefore can be recovered and reused. On the other hand, the reaction time can be shortened by $\mathrm{Sn}\left[\mathrm{N}\left(\mathrm{SO}_{2} \mathrm{C}_{8} \mathrm{~F}_{17}\right)_{2}\right]_{4}$ in FBS using $35 \%$ aqueous $\mathrm{H}_{2} \mathrm{O}_{2}$ as oxidant, and moreover, the problem of oxidant $\mathrm{H}_{2} \mathrm{O}_{2}$ decomposing can be prevented. High yields and purities of lactone can also be obtained by the catalytic BV oxidation process under mild conditions.

In these respects, the fluorous Sn-based catalysts in FBS show excellent performance for BV oxidation reaction, and in the meantime, however, the toxicity of organic catalysts is in most cases unavoidable resulting in the limitation of its wide applications.

\section{Heterogeneous Sn Catalysts}

\section{Sn-zeolite based catalysts}

Zeolites also named as "molecular sieves", as a kind of selective heterogeneous catalysts, are used widely in many important chemical processes. The microporous crystalline 
Table 1 BV oxidations of ketones by using $\mathrm{Sn}\left[\mathrm{N}\left(\mathrm{SO}_{2} \mathrm{C}_{8} \mathrm{~F}_{17}\right)_{2}\right]_{4}$ as catalyst [31]

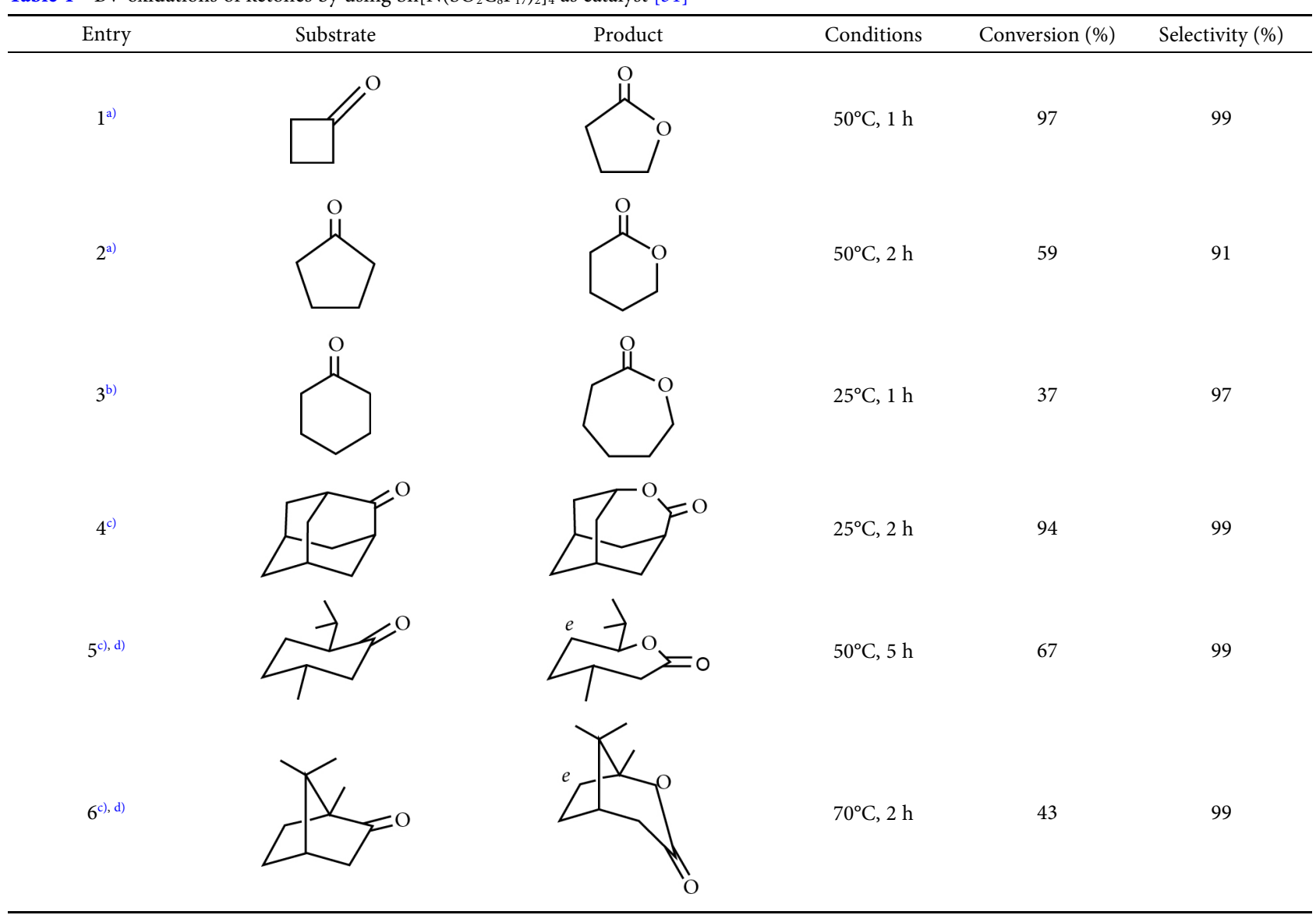

a) Substrate $2 \mathrm{mmol}, \mathrm{H}_{2} \mathrm{O}_{2}$ aq. $(35 \%) 2 \mathrm{mmol}, \mathrm{Sn}\left[\mathrm{N}\left(\mathrm{SO}_{2} \mathrm{C}_{8} \mathrm{~F}_{17}\right)_{2}\right]_{4} 1 \mathrm{~mol} \%$, solvent $\left(\mathrm{CF}_{3} \mathrm{C}_{6} \mathrm{~F}_{11} 3 \mathrm{ml}\right.$, 1,4-dioxane $\left.3 \mathrm{~mL}\right)$; b) substrate $1 \mathrm{mmol}$, $\mathrm{H}_{2} \mathrm{O}_{2}$ aq. (35\%) $0.8 \mathrm{mmol}, \mathrm{Sn}\left[\mathrm{N}\left(\mathrm{SO}_{2} \mathrm{C}_{8} \mathrm{~F}_{17}\right)_{2}\right]_{4} 1 \mathrm{~mol} \%$, solvent $\left(\mathrm{CF}_{3} \mathrm{C}_{6} \mathrm{~F}_{11} 2 \mathrm{ml}\right.$, 1,4-dioxane $\left.2 \mathrm{ml}\right)$; c) substrate $2 \mathrm{mmol}$, $\mathrm{H}_{2} \mathrm{O}_{2}$ aq. $(35 \%) 2 \mathrm{mmol}$, $\mathrm{Sn}\left[\mathrm{N}\left(\mathrm{SO}_{2} \mathrm{C}_{8} \mathrm{~F}_{17}\right)_{2}\right]_{4} 1 \mathrm{~mol} \%$, solvent $\left(\mathrm{CF}_{3} \mathrm{C}_{6} \mathrm{~F}_{11} 3 \mathrm{ml},\left(\mathrm{CH}_{2}\right)_{2} \mathrm{Cl}_{2} 3 \mathrm{~mL}\right)$; d) $3 \mathrm{~mol} \%$ of catalyst was employed with respect to the ketone; e) regioselectivity ( > 99\%) determined by GC and ${ }^{1} \mathrm{H}$ NMR.

frameworks of most aluminosilicates have high hydrothermal stability and feature attractive shape and transitionstate selectivity effects $[33,34]$. Since zeolite material possesses microporous character, a zeolite-catalyzed reaction typically involves four steps. Firstly, reactant molecules diffuse to the active sites in the zeolite through its micropores, and are adsorbed at the active sites in the second step; thirdly, chemical reaction happens to give the product; and finally diffusion of the adsorbed product through channels in the zeolite [35]. The microporous character endows zeolite more amount of active sites existing external and/or internal pores, thus zeolite has been used widely in a variety of catalytic processes, including great numbers of oxidations and, specifically, the BV reaction for that it allows the incorporation of transition metals in framework [36-39].

Corma et al. [40-43] firstly reported the tin-containing beta zeolites (Sn-beta zeolite) as the efficient catalysts for the $\mathrm{BV}$ reaction with $35 \%$ aqueous $\mathrm{H}_{2} \mathrm{O}_{2}$ as oxidant because of the special character of Sn species with Lewis acids, and they pointed out that the Sn-beta zeolite catalyst retained its high chemoselectivity in carrying out the BV oxidation of unsaturated ketones, such as bicyclohept-3-en-1-one, and a high conversion of $>95 \%$ with $100 \%$ selectivity for lactones were obtained, which could only be reached by using enzymes as catalysts. While, using $m$-chloroperbenzoic acid (mCPBA) as an oxidant would lead to the production of lactones with a relatively low selectivity of $29 \%$ and large amount of epoxide by-products [40]. This convincingly indicates that $\mathrm{Sn}$-beta zeolite can be an excellent alternative for percarboxylic acids when using $\mathrm{H}_{2} \mathrm{O}_{2}$ as oxidant. Moreover, the corresponding catalytic mechanism is given as following: the carbonyl group of ketone is activated by the $\mathrm{Sn}$ atoms in beta zeolite, which are Lewis acids, followed by a nucleophilic attack by $\mathrm{H}_{2} \mathrm{O}_{2}$ on the carbonyl carbon to 
give an intermediate similar to the "Criegee" adduct; and then the intermediate rearranges to produce the end product, which was reviewed by Sanchidrián et al. [28].

However, there still exist some problems, such as much low Sn content and some amount of the Sn active sites embedded, resulting in the active activity not fully exhibited. In order to improve the Sn species amount and expose enough active sites, recently, Li et al. [44] reported nanosized Sn-beta zeolite (Sn-beta-PS) with Sn content of $6.2 \mathrm{wt} . \%$ which was synthesized by the solid-gas reaction of highly dealuminated beta zeolite with $\mathrm{SnCl}_{4}$ vapor (as shown in Fig. 1), and this Sn-beta-PS material shows high and stable catalytic activity for the BV oxidation of 2-adamantanone with hydrogen peroxide, e.g., a high selectivity of above $99 \%$ has been obtained when using $\mathrm{C}_{6} \mathrm{H}_{5} \mathrm{Cl}$ as solvent, and $80.5 \%$ conversion rate with $99 \%$ selectivity can still be obtained even after 5 cycles. The post synthesis strategy not only improves the content of isolated Sn species, but also makes the Sn active sites exposed enough, leading to the high BV reaction efficiency. By adopting similar method, Sn-beta zeolites with 3.8 wt.\% $\mathrm{SnO}_{2}$ (i.e., $\mathrm{Si} / \mathrm{Sn}=83$, see the SEM images in Fig. 2) have also been synthesized, which were proved to be efficient catalysts for BV oxidation of cyclohexanone to $\varepsilon$-caprolactone with high selectivities of above $98 \%$ of the target product [45].

Besides the Sn active sites content, the structure of the zeolite also affects the activity for BV oxidation. Stannosilicate zeolites with nanosheet morphology and MFI topology (Sn-MFI-ns, as shown in Fig. 3) show much higher catalytic activity than bulk Sn-MFI in the BV oxidation of cyclic ketones using $\mathrm{H}_{2} \mathrm{O}_{2}$ [46]. Compared with bulk Sn-MFI, Sn-MFI-ns shows a significant increase in catalytic activity for the $\mathrm{BV}$ oxidation of cyclic ketones from the data in Table 2, e.g., the conversion rate and selectivity of target

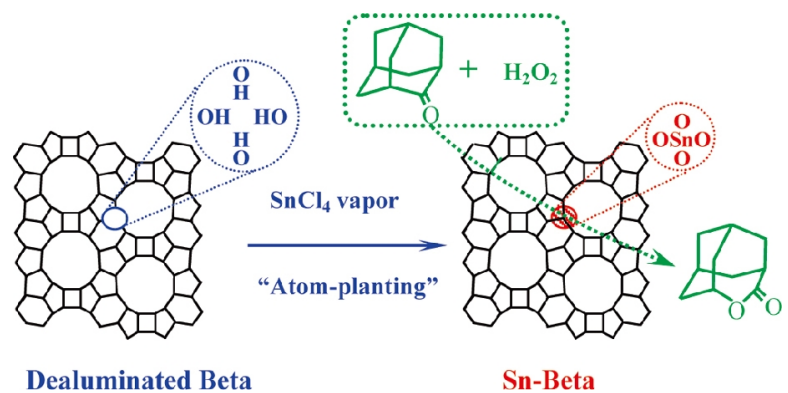

Figure 1 Strategy for post-synthesis of Sn-beta through combination of dealumination with solid-gas reaction (atom-planting method) as a catalyst for BV oxidation of 2-admantanone. Reprinted with permission from Ref. [44], Copyright 2011, American Chemical Society.

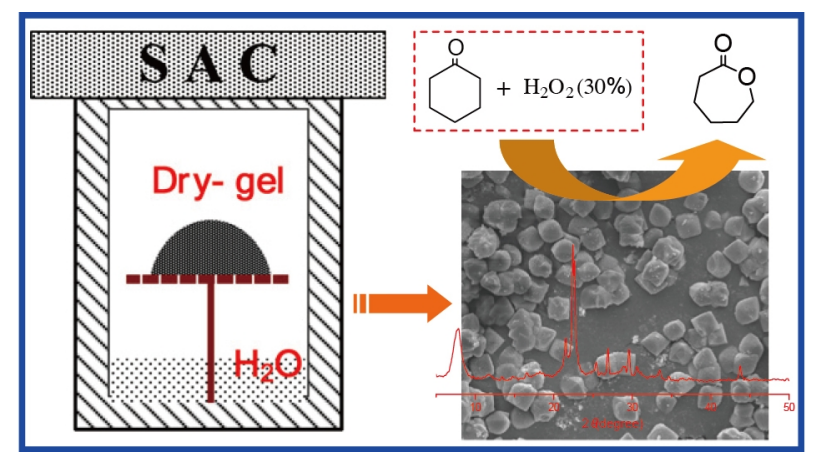

Figure 2 Steam-assisted conversion (SAC) method for synthesis of Sn-beta zeolite as a catalyst for BV oxidation of cyclohexanone. Reprinted with permission from Ref. [45], Copyright 2013, Elsevier.

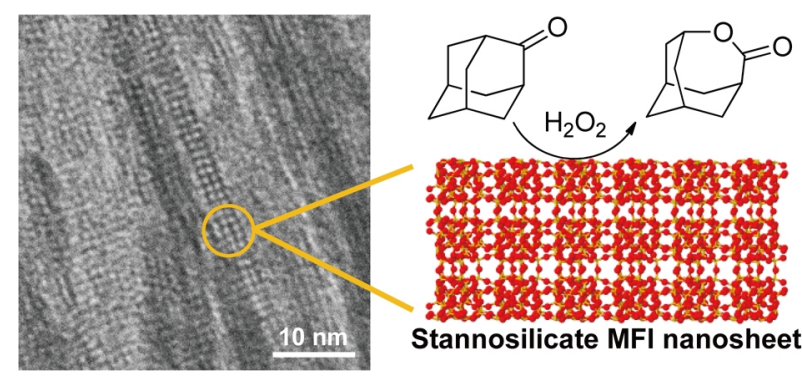

Figure 3 TEM image and schematic structure of Sn-MFI-ns. Reprinted with permission from Ref. [46], Copyright 2011, American Chemical Society.

product is $92 \%$ and $>98 \%$, respectively on Sn-MFI-ns, while the values are $13 \%$ and $95 \%$, respectively on bulk Sn-MFI. The activities and efficiencies of Sn-MFI-ns were comparable to those of Sn-MCM-41 with Sn sites embedded in a mesoporous amorphous silica framework, indicating that the external Sn sites in Sn-MFI-ns have a performance similar to the latter, while the former show superior thermal and hydrothermal stability than Sn-MCM-41. The high catalytic activity of Sn-MFI nanosheet should be due to the surface area which makes the Sn active sites exposed enough resulting in the activity enhancement of BV oxidation reaction. On the other hand, the less diffusion limitations to the substrate with a large molecular dimension also contribute to the high catalytic activity of Sn-MFI nanosheet. Thus, the catalytic activity for BV oxidation would be enhanced for the zeolite with mesoporous structure, e.g., mesoporous Sn-beta zeolites of 20-50 $\mathrm{nm}$ in pore diameter (see the transmission electron microscopy (TEM) images in Fig. 4) exhibit comparable and even higher per formance than the conventional Sn-beta zeolites for the BV oxidation of 2-adamantanone by $\mathrm{H}_{2} \mathrm{O}_{2}$ owing to its hierarchical micro/mesoporous structures of the former [47]. 
Table 2 Catalytic activities of Sn-containing catalysts for the BV oxidation of 2-adamantanone using $\left.\mathrm{H}_{2} \mathrm{O}_{2}{ }^{\mathrm{a}}\right)[46]$

\begin{tabular}{|c|c|c|c|c|c|c|}
\hline Catalyst & $\mathrm{H}_{2} \mathrm{O}_{2}{ }^{\text {b) }}$ (equiv) & Conversion $^{c)}(\%)$ & Efficiency $^{\mathrm{d})}(\%)$ & $\mathrm{TON}^{\mathrm{e})}$ & $\operatorname{TOF}^{f}\left(h^{-1}\right)$ & Selectivity $^{\mathrm{g})}(\%)$ \\
\hline Bulk Sn-MFI & 1.5 & 13 & 13 & 17 & 5 & 95 \\
\hline Bulk Sn-beta & 1.5 & 99 & 92 & 143 & 210 & $>98$ \\
\hline Sn-MCM-41 & 1.5 & 99 & 82 & 137 & 58 & $>98$ \\
\hline Sn-MFI-ns & 1.5 & 92 & 8 & 122 & 38 & $>98$ \\
\hline Sn-MFI-ns-e ${ }^{\mathrm{h})}$ & 1.5 & 87 & 75 & 120 & 37 & $>98$ \\
\hline Bulk Sn-MFI & 0.6 & 15 & 28 & 23 & 9 & $>98$ \\
\hline Sn-MCM-41 & 0.6 & 62 & 99 & 99 & 91 & $>98$ \\
\hline Sn-MFI-ns & 0.6 & 62 & 99 & 104 & 86 & $>98$ \\
\hline Sn-MFI-ns-sil ${ }^{i)}$ & 1.5 & 39 & 49 & 51 & 12 & $>98$ \\
\hline Sn-MCM-41-sil & 1.5 & 76 & 68 & 91 & 20 & $>98$ \\
\hline $\mathrm{SnO}_{2}-\mathrm{MCM}-41$ & 1.5 & 3 & 3 & 4 & 2 & 96 \\
\hline
\end{tabular}

a) Reaction conditions: catalyst, $0.66 \mathrm{~mol} \%$ of $\mathrm{Sn}$ with respect to the ketone; ketone, $1 \mathrm{mmol} ; 50 \% \mathrm{H}_{2} \mathrm{O}_{2}, 1.5$ or $0.6 \mathrm{mmol}$; dioxane, 3 g; $75^{\circ} \mathrm{C}, 16 \mathrm{~h}$; b) $\mathrm{H}_{2} \mathrm{O}_{2}$ equivalents with respect to ketone; $\left.\mathrm{c}\right)$ conversion $=($ moles of ketone converted $) /($ initial moles of ketone $) \times 100$; $)$ oxidant efficiency $=($ moles of ketone converted $) /\left(\right.$ moles of $\mathrm{H}_{2} \mathrm{O}_{2}$ consumed $) \times 100$; e) Turnover number $(\mathrm{TON})=($ moles of substrate converted $) /($ moles of tin centers) at 16 h; $\mathrm{f})$ turnover frequency $(\mathrm{TOF})=($ moles of substrate converted $) /($ moles of tin centers $)$ per hour calculated from $1 \mathrm{~h}$ conversions, except Sn-beta at 15 min; $\mathrm{g}$ ) selectivity $=($ moles of product $) /($ moles of ketone reacted $) \times 100 ; \mathrm{h})$ “-e" indicates the presence of extra framework tin; $\mathrm{i})$ "-sil" indicates the catalyst is silylated.
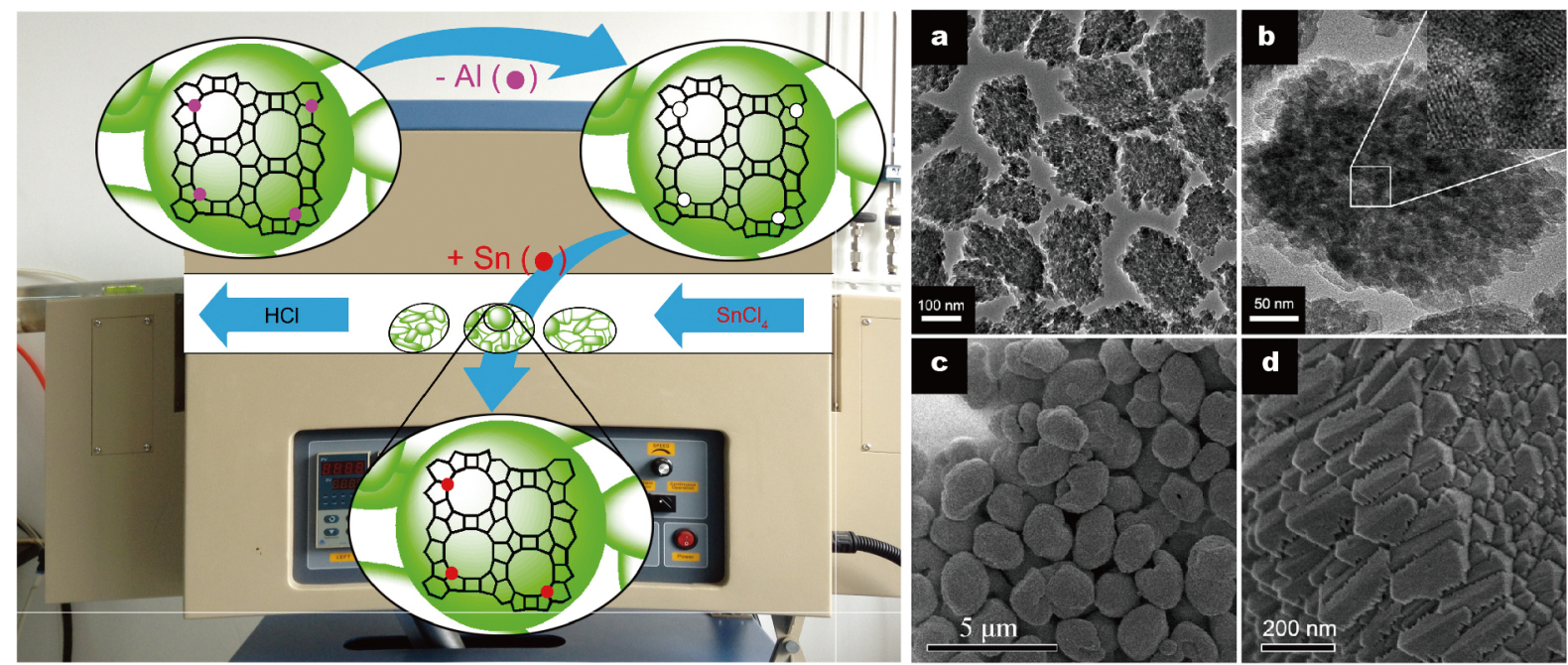

Figure 4 Strategy for synthesis of mesoporous Sn-beta and TEM (a, b) images of Meso-Sn-beta; SEM (c, d) images at different magnifications. Reprinted with permission from Ref. [47], Copyright 2014, Royal Society of Chemistry.

Delaminated zeolite with novel structure demonstrates an excellent catalytic performance for BV oxidation. Recently, Ouyang et al. [48] reported a heteroatom-substituted delaminated zeolites by the surfactant-free exfoliation of a MWW-type borosilicate zeolite precursor into a delaminated zeolite (shown as Fig. 5). Especially, the $\mathrm{Sn}$ substituted delaminated zeolites (Sn-DZ-1) exhibit much higher conversion rate than Sn-beta for the BV oxidation of 2-adamantanone according to the data in Table 3. The enhanced catalytic activity of the delaminated Sn-DZ-1 is due to the three-dimensional (3D) structure which accelerates the species diffusion and in turn resulting in the activity enhancement. Following this, Liu et al. [49] synthesized a novel stannosilicate with the MWW topology, Sn-MWW, by hydrothermally synthesizing in alkali medium using boric acid as a crystallization-supporting agent, in which the Sn species were incorporated in the framework, occupying mainly the tetrahedral sites. A mild acid treatment was conducted on the Sn-MWW precursors (Sn-MWW lamellar) to induce a structural transformation to tin-containing materials structurally analogous to MCM-56 (Fig. 6). The post-synthesized Sn-MCM-56, par- 


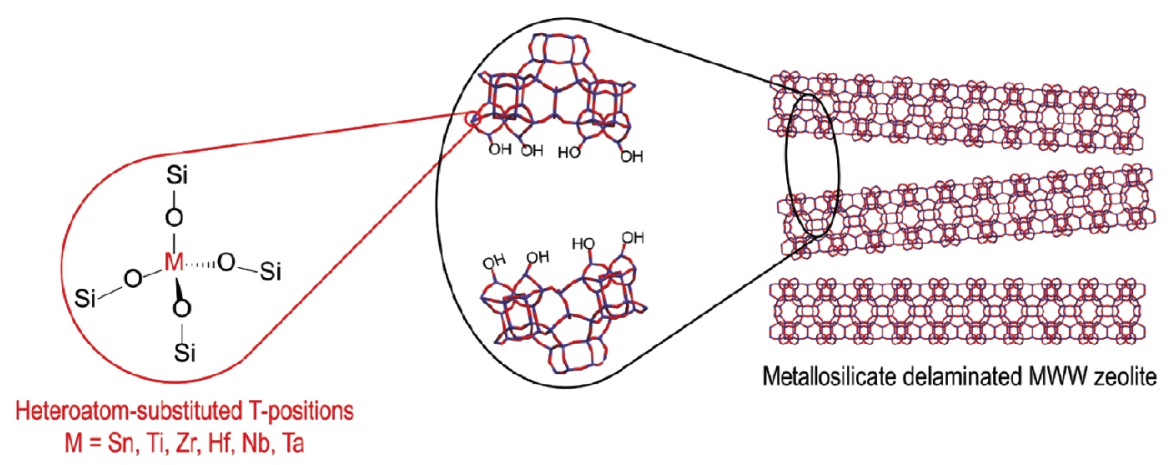

Figure 5 Schematic diagram of the surfactant-free exfoliation of a MWW-type borosilicate zeolite precursor into a delaminated zeolite consisting of high density of silanol nests and the reoccupation of the silanol nests with various heteroatoms. Reprinted with permission from Ref. [48], Copyright 2015, American Chemical Society.

Table 3 BV Oxidation of 2-adamantanone by Sn-DZ-1 and Sn-beta ${ }^{a)}[48]$

\begin{tabular}{|c|c|c|c|c|}
\hline \multirow{2}{*}{ Substrate } & \multicolumn{2}{|l|}{ Sn-DZ-1 ${ }^{\text {b) }}$} & \multicolumn{2}{|l|}{ Sn-beta ${ }^{c)}$} \\
\hline & Initial rates $^{\mathrm{d})}\left[\mathrm{mol} \mathrm{h}^{-1}(\mathrm{~mol} \mathrm{Sn})^{-1}\right]$ & Conversion $^{\mathrm{e}}(\%)$ & Initial rates $^{\mathrm{d})}\left[\mathrm{mol} \mathrm{h}^{-1}(\mathrm{~mol} \mathrm{Sn})^{-1}\right]$ & Conversion $^{\mathrm{e}}(\%)$ \\
\hline & 866 & 97 & 1963 & 99 \\
\hline & 825 & 95 & 417 & 66 \\
\hline & 688 & 94 & 366 & 57 \\
\hline
\end{tabular}

a) Reaction conditions: 30 wt. $\% \mathrm{H}_{2} \mathrm{O}_{2}$ in $\mathrm{H}_{2} \mathrm{O}, \mathrm{H}_{2} \mathrm{O}_{2}$ /ketone = 1.5:1 by mol, 1,4-dioxane as solvent, $75^{\circ} \mathrm{C}$, molar ratio of Sn to ketone $=0.0066: 1 ; \mathrm{b}$ ) $\mathrm{Si} / \mathrm{Sn}=65 ; \mathrm{c}) \mathrm{Si} / \mathrm{Sn}=100$; d) initial rates are calculated by dividing the moles of substrates converted per hour when conversion rate of substrate is under $20 \%$ by moles of Sn sites; e) conversion $=($ moles of ketone converted at $24 \mathrm{~h}) /($ initial moles of ketone $) \times 100$. Selectivities for all these catalysts are nearly $100 \%$.

tially delaminated for layered zeolitic structure, composed of partially delaminated MWW sheets and possessed larger external surface as well as more open reaction space. More importantly, the prepared Sn-MCM-56 appears to be more efficient than Sn-MWW in the BV oxidation of 2-adamantanone with $\mathrm{H}_{2} \mathrm{O}_{2}$ as oxidant, and the conversion rate of the former is $10 \%$ higher than that of the Sn-MWW at the same Sn content (Fig. 7a) or at the same reaction time (Fig. $7 b)$. This is due to that the analogue Sn-MCM-56 can effectively alleviate the steric restriction and diffusion limitation to bulky molecules that the microporous zeolite catalysts usually encountered. Moreover, the Sn-MCM-56 turned to be more active than Sn-beta when tert-butyl hydroperoxide was employed as an oxidant, and because of that the stan- nosilicates with large pore sizes are thus highly desirable to overcome the sluggish diffusion problems encountered in the BV oxidations. Expectedly, the active and most selective Sn-beta zeolite, as a fascinating catalyst system for heterogeneous catalysis will continuously play an important role in the catalytic applications for BV oxidations.

Different from the framework Sn-beta zeolites, Snexchanged zeolite, such as $\mathrm{Sn}\left(\right.$ salen)-NaY with $\left[\mathrm{Sn}(\text { salen) }]^{2+}\right.$ complex moiety in situ immobilized into $\mathrm{NaY}$ zeolite, also showed impressive catalytic performance (with high selectivity) in BV oxidation of various cyclic ketones including 2-adamantanone, cyclohexanone, cyclopentanone, 4-methylcyclohexanone, and 2-methylcyclohexanone [50]. However, tert-butyl hydroperoxide (tert-BuOOH) was 


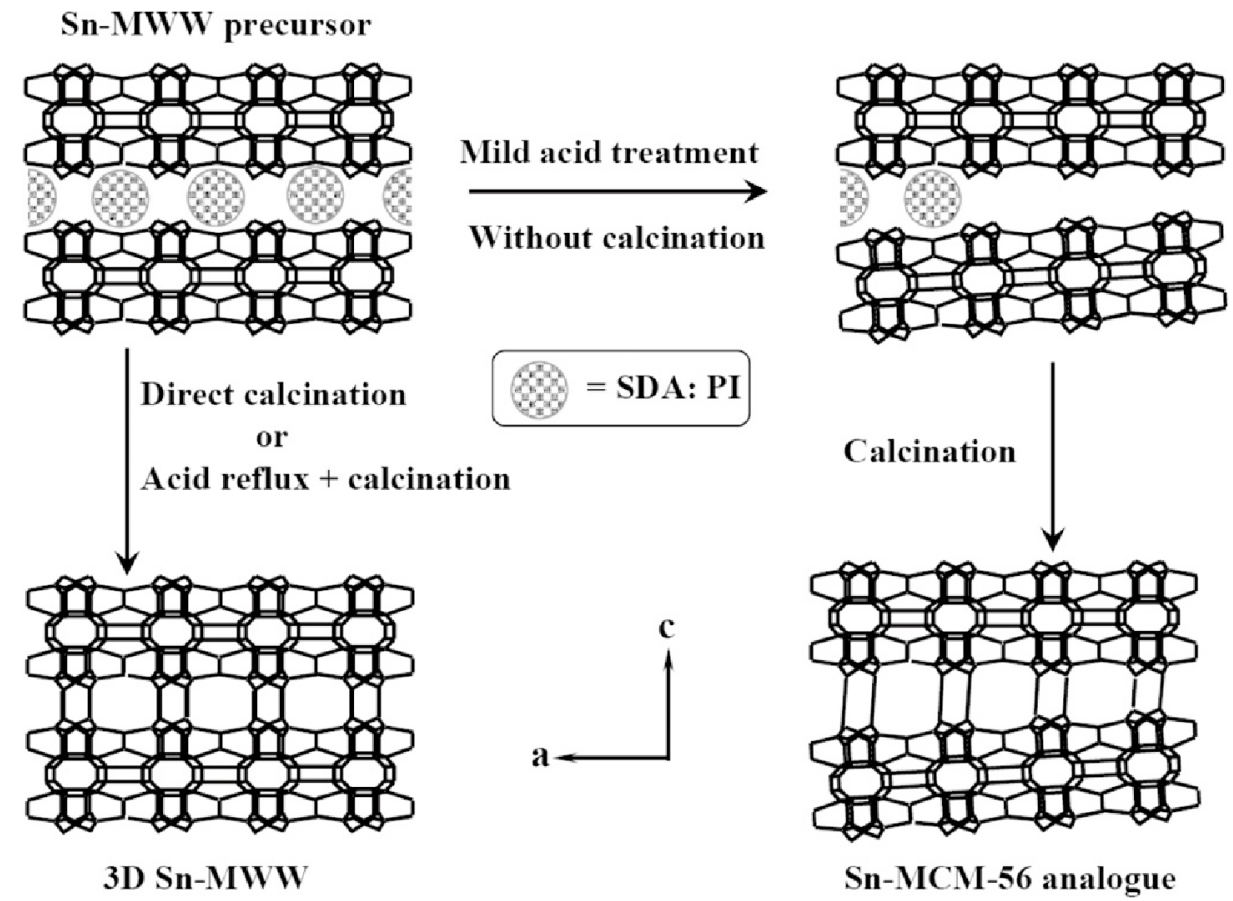

Figure 6 Schematics for the formation of Sn-MCM-56 analogues from the Sn-MWW precursors. Reprinted with permission from Ref. [49], Copyright 2013, Elsevier.
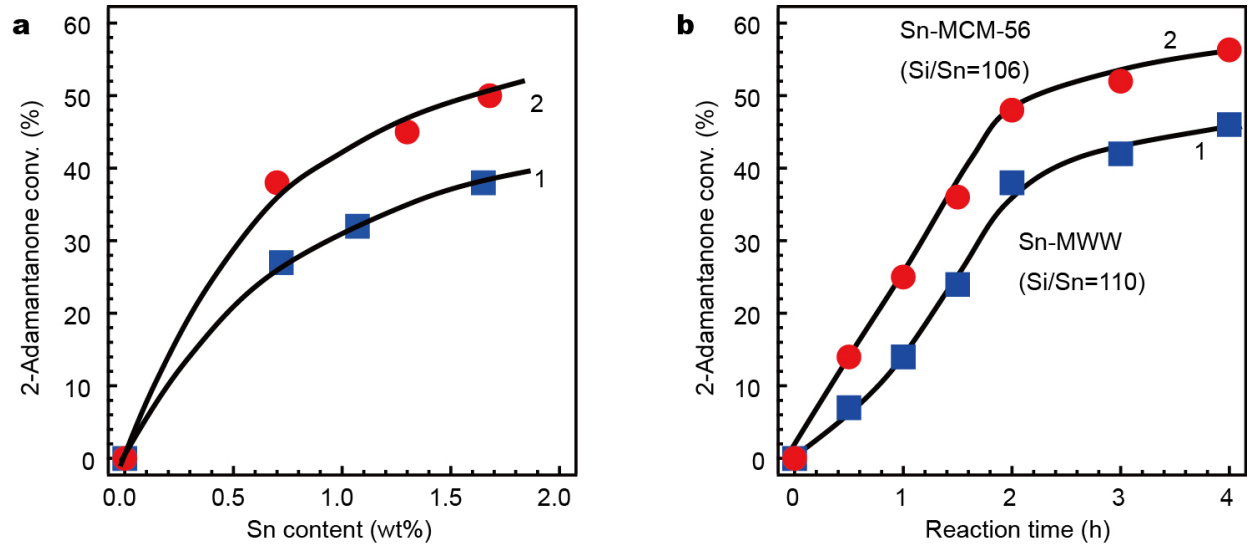

Figure 7 Dependence of ketone conversion on the Sn content (a) and the reaction time (b) in the BV oxidation of 2-adamantanone over Sn-MWW (1) and Sn-MCM-56 (2). Reprinted with permission from Ref. [49], Copyright 2013, Elsevier.

used as the oxidant during the BV oxidation by using $\mathrm{Sn}$ (salen)-NaY as catalyst, which is expensive and therefore undesirable in applications.

In a word, Sn-based zeolite materials are excellent catalysts for BV oxidation reaction when using $\mathrm{H}_{2} \mathrm{O}_{2}$ as oxidant. Especially, in the $\mathrm{BV}$ oxidations of unsaturated ketone, the chemoselectivity is especially high by using Sn-based zeolite molecular sieves as catalysts with the target product being frequently $100 \%$ ester or lactone. However, the catalytic performances for BV oxidation of bulky cycle ketones with large molecular weights need to be enhanced because of micropore size limitation of the Sn-based zeolite molecular sieves.

\section{Sn-containing mesoporous material catalysts}

Aluminosilicate zeolites and zeolitic metallosilicate containing isolated transition metal ions have been extensively used as solid Brønsted acid catalysts in petrochemical processing and solid Lewis acid catalysts for redox reactions, thanks to their uniform, small pore size, flexible frameworks, and controlled chemistry [51-53]. However, their applications are limited to small molecules that can diffuse 
through the small cavities ( $<1.5 \mathrm{~nm}$ typically) and the narrow channels $(<0.8 \mathrm{~nm})$ between the cavities [54]. It has been widely demonstrated that the mass transfer limitations are an important issue in industrial applications involving zeolitic materials [55-57]. To circumvent the diffusional limitations imposed by zeolitic structures, mesoporous materials with pore diameters in between $2-50 \mathrm{~nm}$ would be desirable. Since mesoporous material (MCMM41S) has been reported by researchers at Mobil in 1992 [58], a series mesoporous materials, such as hexagonal honeycomb MCM-41, cubic mesophase MCM-48 and layered mesophase MCM-50, have been reported sequentially.

Since Corma et al. [59,60] firstly reported Sn-MCM-41 as an efficient catalyst for BV oxidation, mesoporous Sn-MCM-41 opens up a new class of heterogeneous catalysts for the BV reaction with $\mathrm{H}_{2} \mathrm{O}_{2}$. They developed, for the first time, a new class of heterogeneous catalyst Sn-MCM-4 by a direct hydrothermal synthesis method, and this catalyst exhibited high performance for BV oxidation of adamantanone with $>98 \%$ conversion rate and a selectivity of $>98 \%$. Also, the Sn-MCM-4 catalyst can effectively catalyze the BV oxidations of cyclohexanone and unsaturated ketone, such as dihydrocarvone [59]. Following this, they employed a post treatment method to graft $\mathrm{Sn}$ species onto MCM-41, in which Sn has been incorporated in a post synthesis treatment by a grafting procedure ( $\left(\mathrm{n}_{\text {graft }}-\mathrm{MCM}-41\right)$, to yield isolated, active and well-accessible metal centers, and they found that the prepared $\mathrm{Sn}_{\text {graft }}-\mathrm{MCM}-41$ showed excellent catalytic activity for BV oxidation of adamantanone with a selectivity of $>99 \%$ [60]. It is satisfactory that the mesoporous molecular sieve Sn-MCM-41 can also be efficient for the BV oxidation of large molecule substrates, such as cyclocitral, safranal, myrtenal, cinnamaldehyde, $p$-methoxycinnamaldehyde and piperonal [61]. The mesoporous Sn-MCM-41 provides higher conversion rates for BV oxidation than by Sn-beta zeolite, which can be attributed to the larger pore diameter and less sterical hindrance on the diffusion by mesoporous molecular sieves [62].

In order to overcome the limitation of intraparticle diffusion of substrates at the active sites incorporated in the mesoporous framework, submicrometer-sized Sn-MCM-41 particles (Sn-MCM-41/SMPs) with short mesopore channels and stable $\mathrm{Sn}$ species are welcome. As expected, these Sn-MCM-41/SMPs displayed higher initial reaction rates than Sn-MCM-41 for the BV oxidation of adamantanone with $\mathrm{H}_{2} \mathrm{O}_{2}$, for that the shorter mesoporous channels in former play an important role in accelerating the diffusion rate of reactant molecules in the pores [63]. As another kind of hexagonal mesoporous material, Sn-SBA-15 (Fig. 8) also showed much higher catalytic activity for the BV oxidation of cyclohexanone to $\mathcal{E}$-caprolactone than Sn-MCM-41 from the data in Table 4, e.g., the conversion rate and selectivity can be improved from $37.3 \%-52.2 \%$ to $46.4 \%-74.4 \%$ on Sn-MCM- 41 , and $67.6 \%-82.6 \%$ to $72.5 \%-86.3 \%$ on Sn-SBA- 15 , respectively. The enhanced catalytic activity is due to the larger pore size of Sn-SBA-15 $(5.5-5.6 \mathrm{~nm})$ than that of Sn-MCM-41 $(2.7-2.7 \mathrm{~nm})$, and furthermore, this heterogeneous mesoporous Sn-SBA-15 catalyst was reusable without any appreciable loss in activity and selectivity after three cycles [64]. As mentioned above, for small molecule size substrates, Sn-beta zeolite with a regular pore size of 0.3-0.7 $\mathrm{nm}$ in diameter is an efficient catalyst or BV oxidation, and the sterical hindrance over substrate/product diffusion in micropore systems makes the mesoporous molecular sieve, such as Sn-MCM-41 and SBA-15, of 2-nm in channel diameter much more desirable.

Compared to hexagonal honeycomb Sn-MCM-41, cubic mesophase Sn-MCM-48 would exhibit much higher catalytic performance, as an example, Sn-MCM-48 exhibited conversion rates of $51 \%-100 \%$ and $53 \%-86 \%$ for adamantanone and norcamphor BV oxidations respectively by using $\mathrm{H}_{2} \mathrm{O}_{2}$ as oxidation agent, while Sn-MCM-41 exhibited conversion rates of $42 \%-90 \%$ and $32 \%-73 \%$, accordingly [65]. Moreover, the selectivity to adamantanone-lactone as well as norcamphor-lactone was almost $100 \%$ for the cubic mesophase Sn-MCM- 48 catalyst. This is mainly due to the faster diffusion of reactants and products in cubic pore channels than that in hexagonal pore channels. In addition, the cubic pore channels of Sn-MCM-48 make the Sn active sites exposed enough, and in contrast, partial amount of $\mathrm{Sn}$ was located in the pore walls of the planar hexagonal Sn-MCM-41 and inaccessible for the reactant molecules, thus, not all Sn sites will function as active Lewis acid sites and contribute to the overall catalytic activity at the same extent. This is not contradictory with the report by Corma et al. [66] that the catalytic active center in Sn-beta and Sn-MCM-41 zeolites for BV oxidations involves not only the framework Sn sites but also associated "basic" oxygen atoms that stabilize the reaction transition state through hydrogen bonding.

Among the reported cubic mesoporous silica materials, SBA-16 appears to be one of the best candidates as catalytic support or absorbent because of the enhanced thermal stability due to the thick wall, economical synthesis with inexpensive silica sources, and large pores [67-70]. Sn incorporated SBA-16 (Sn-SBA-16), as an ordered cubic-like 

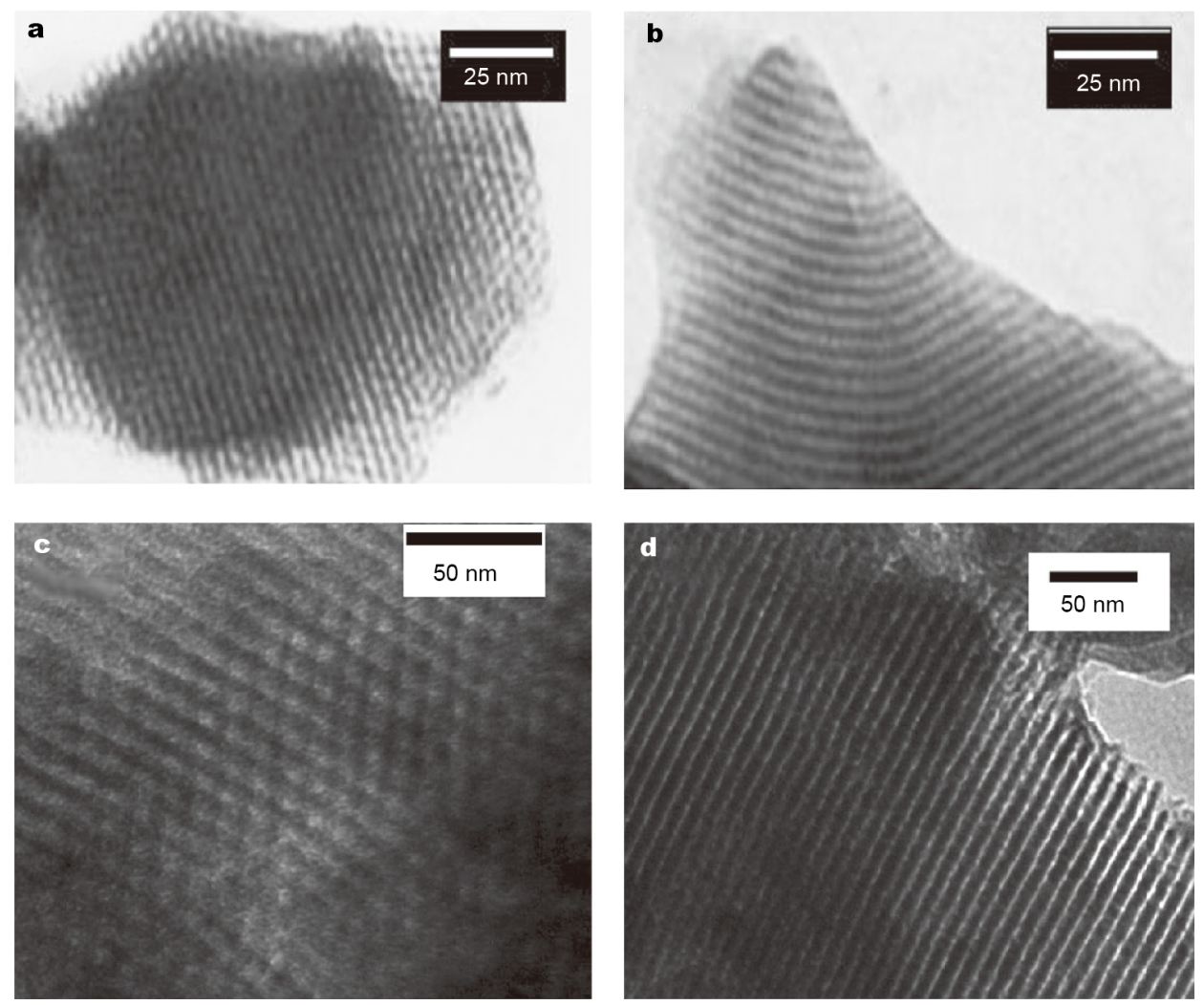

Figure 8 TEM images of Sn-MCM-41 (a, b) and Sn-SBA-15 (c, d). Reprinted with permission from Ref. [64], Copyright 2015, Springer.

Table 4 Catalytic activities of different catalyst for the BV oxidation of cyclohexanone using $\mathrm{H}_{2} \mathrm{O}_{2}$ as oxidant [64]

\begin{tabular}{ccccc}
\hline Catalyst & Conversion (\%) & Selectivity (\%) & Yield (\%) & TON \\
\hline / & 1.4 & 0 & 0 & 0 \\
Si-MCM-41 & 1.6 & 0 & 0 & 0 \\
Si-SBA-15 & 1.5 & 0 & 0 & 0 \\
SnCl $_{4} \cdot 5 \mathrm{H}_{2} \mathrm{O}$ & 5.5 & 0 & 27.3 & 70 \\
Sn-MCM-41(100) & 37.3 & 73.3 & 39.3 & 79 \\
Sn-MCM-41(50) & 47.4 & 82.6 & 36.9 & 62 \\
Sn-MCM-41(30) & 48.4 & 76.2 & 35.3 & 64 \\
Sn-MCM-41(10) & 52.2 & 67.6 & 33.6 & 87 \\
Sn-SBA-15(100) & 46.4 & 72.5 & 60.1 & 114 \\
Sn-SBA-15(50) & 69.6 & 86.3 & 59.9 & 111 \\
Sn-SBA-15(30) & 72.5 & 82.6 & 58.2 & 108 \\
Sn-SBA-15(10) & 74.4 & 78.2 & \\
\hline
\end{tabular}

$0.1 \mathrm{~mol}$ cylcohexanone; $30 \% \mathrm{H}_{2} \mathrm{O}_{2} /$ cylcohexanone $(\mathrm{mol})=3 ; 30 \mathrm{~g}$ 1,4-dioxane; $1 \mathrm{~g}$ catalyst; $70^{\circ} \mathrm{C} ; 6 \mathrm{~h}$.

mesoporous structure, gives Lewis acid sites through the framework substitution for silica matrix. More importantly, this Sn-SBA-16 material with tetrahedral-positioned Sn species exhibited high catalytic activity for BV oxidation of adamantanone with $60 \%$ conversion rate and almost $100 \%$ selectivity of lactone at the $\mathrm{pH}$ value of 6 as shown in Fig. 9a [71], which was comparable to the Sn-MCM-48 [65]. In contrast, the Zr incorporated SBA-16 (Zr-SBA-16) shows much lower conversion rate for $\mathrm{BV}$ oxidation of adamantanone as shown in Fig. 9b, further indicating the high catalytic activity of Sn-based SBA-16 catalyst. This is also consistent with the result reported by Nekoksová 

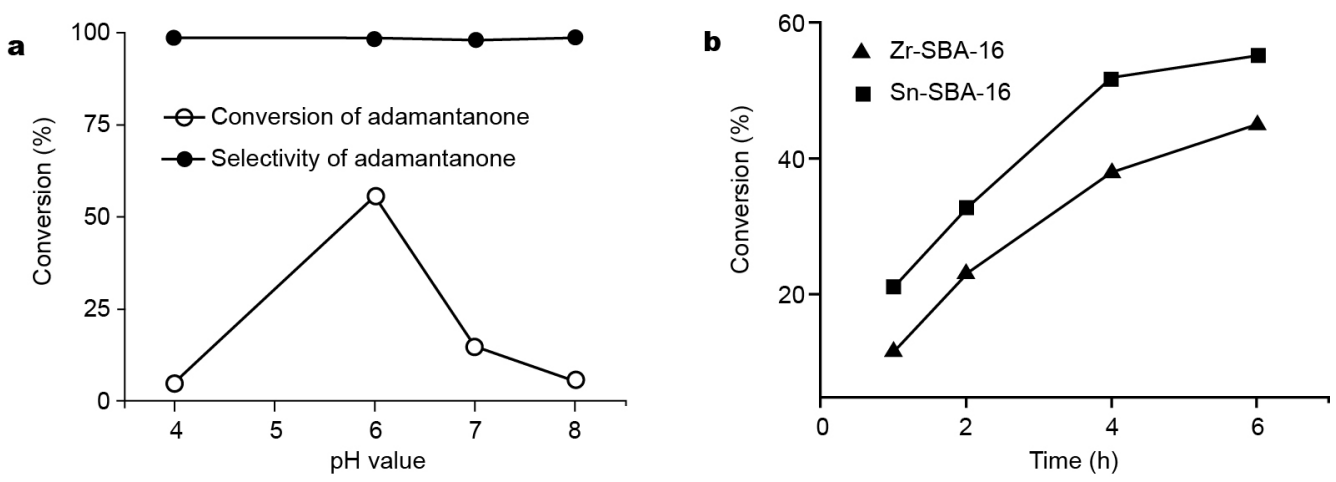

Figure 9 (a) BV oxidation of adamantanone over Sn-SBA-16 synthesized under different $\mathrm{pH}$ values at $6 \mathrm{~h}$ of reaction. (b) BV oxidation of adamantanone over Zr-SBA-16 (with Zr/Si molar ratio in gel $=0.01$ ) and Sn-SBA-16 $(\mathrm{pH} 6$, Sn/Si molar ratio in gel $=0.01)$ at $90^{\circ} \mathrm{C}$. Reprinted with permission from Ref. [71], Copyright 2008, Springer.

et al. [65] in which Sn-MCM-48 with a cubic mesophase of cross-linked 3D channels exhibited higher conversion rates of adamantanone and norcamphor oxidation than Sn-MCM-41 with a block of one-way hexagonal channels. The 3D channels structure facilitates the diffusion of reactants and the transport of products resulting in the enhanced BV oxidation catalytic activity.

At the same time, periodic mesoporous organosilicas (PMO) which are another kind of mesoporous materials are studied extensively, and the PMO materials show high catalytic activity in BV oxidation reaction especially combined with metalloporphyrins. Metalloporphyrins have attracted considerable interest because of their various physicochemical properties [72-75] and their capability to catalyze a variety of oxidation reactions, such as alkene epoxidation and alkane hydroxylation with molecular oxygen [76]. Jeong et al. [77] prepared ordered metal-tetrakis(carboxyphenyl)porphyrin (metal $=\mathrm{Fe}, \mathrm{Cu}, \mathrm{Sn})$ bridged periodic mesoporous organosilicas (M-TCPP-PMO) with high surface areas of about 350-1087 $\mathrm{m}^{2} \mathrm{~g}^{-1}$ and ordered pore channels (TEM images as shown in Fig. 10), and the M-TCPP-PMO exhibits high catalytic activity for BV oxidation of cyclohexanone. Among the high-valent M-porphyrin $(\mathrm{M}=\mathrm{Fe}, \mathrm{Cu}, \mathrm{Sn})$, the Fe-TCPP-PMO demonstrates the highest catalytic activity for the BV oxidation of cyclohexanone. This is due to metal species on the wall of mesoporous silica along with cyclohexanone contribute the high catalytic activity.

Besides mesoporous materials mentioned above, mesoporous silica nanospheres are becoming attractive and prospective in the fields of biology, drug delivery systems and cancer diagnosis and therapy [78-80]. Sn-containing mesoporous silica nanospheres (Sn-MSNSs) with uniform crater-like mesopores (Fig. 11) and strong hydrophobicity exhibited much higher activity in the BV oxidation of

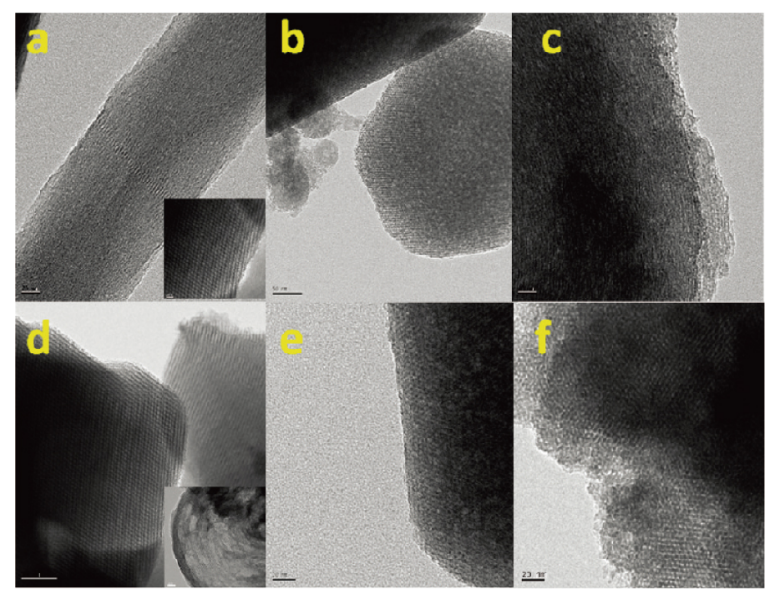

Figure 10 TEM images of samples Fe-TCPP-PMO-10\% (a), Cu-TCPPPMO-10\% (b), Sn-TCPP-PMO-10\% (c), Fe-TCPP-PMO-20\% (d) and Cu-TCPP-PMO-20\% (e), Sn-TCPP-PMO-20\% (f). Reprinted with permission from Ref. [77], Copyright 2011, American Chemical Society.

bulky cyclic ketone and 2-adamantanone than mesoporous Sn-MCM-41 which possessed long one-dimentional (1D) mesopore channels [81]. As can be seen from Table 5, the yield of adamantanone-ester using Sn-MSNSs as catalyst reaches $85 \%$ at a selectivity of above $94 \%$, much higher than that of using mesoporous Sn-MCM-41 as catalyst.

On the whole, the presence of mesoporous structure in tin-containing materials will effectively offset the shortcomings of Sn-based microporous zeolite catalysts of $\leq 1.5$ $\mathrm{nm}$ in its pore size, in which the diffusions of cycle ketone molecules of large molecular weights and/or bulky substituent groups will be greatly hindered. Thus, using mesostructured Sn-based zeolites as catalysts will enable the reactants to diffuse into the mesopore system of the catalysts to access most $\mathrm{Sn}$ active centers, thus resulting in the enhanced conversion rates. 

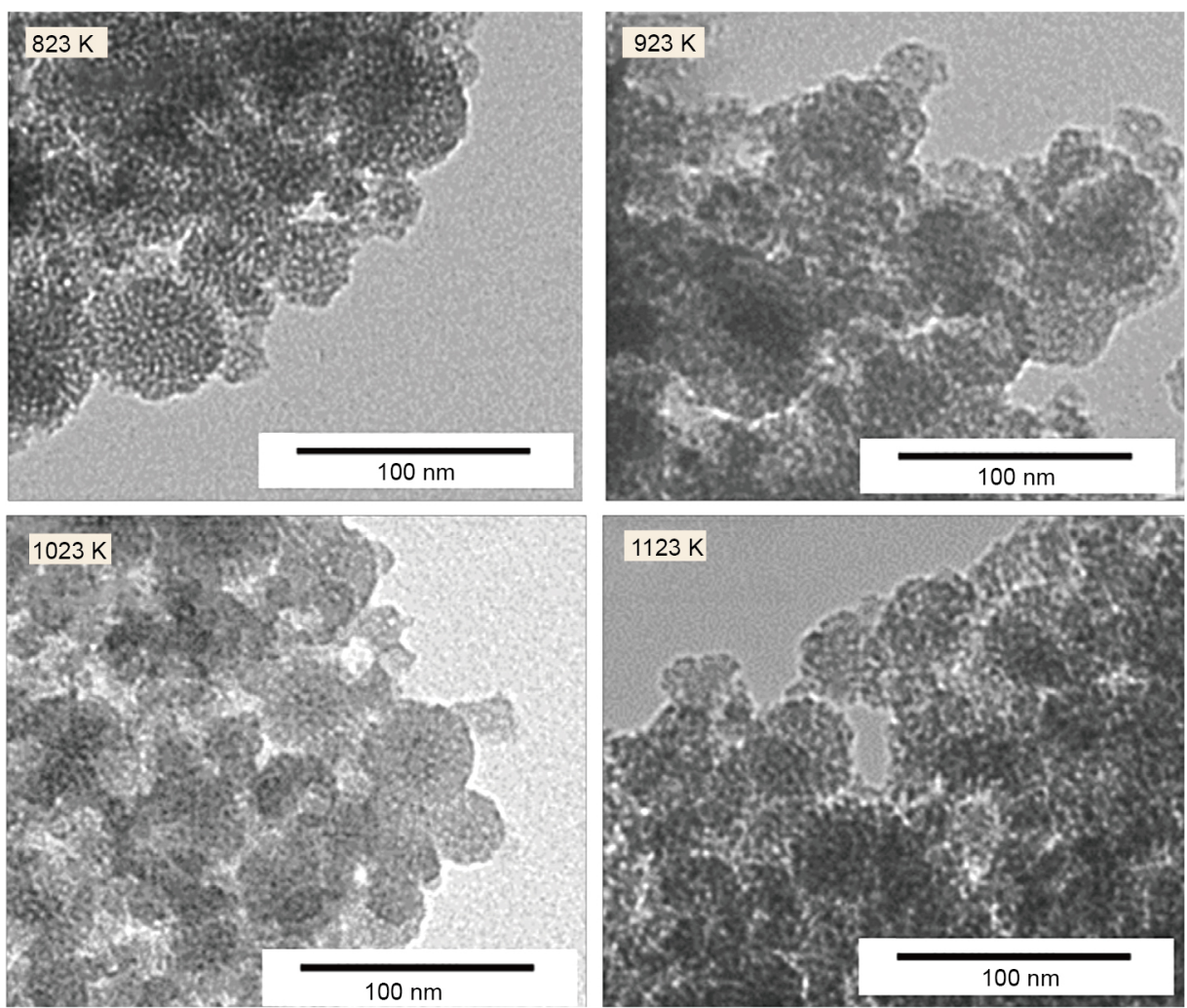

Figure 11 TEM images of Sn-MSNSs products prepared at varied calcination temperatures indicated. Reprinted with permission from Ref. [81], Copyright 2015, Elsevier.

Table 5 Catalytic activity of Sn-MSNSs for the BV oxidation of 2-adamantanone using $\mathrm{H}_{2} \mathrm{O}_{2}$ as oxidant when changing the atomic ratio of Si to Sn [81]

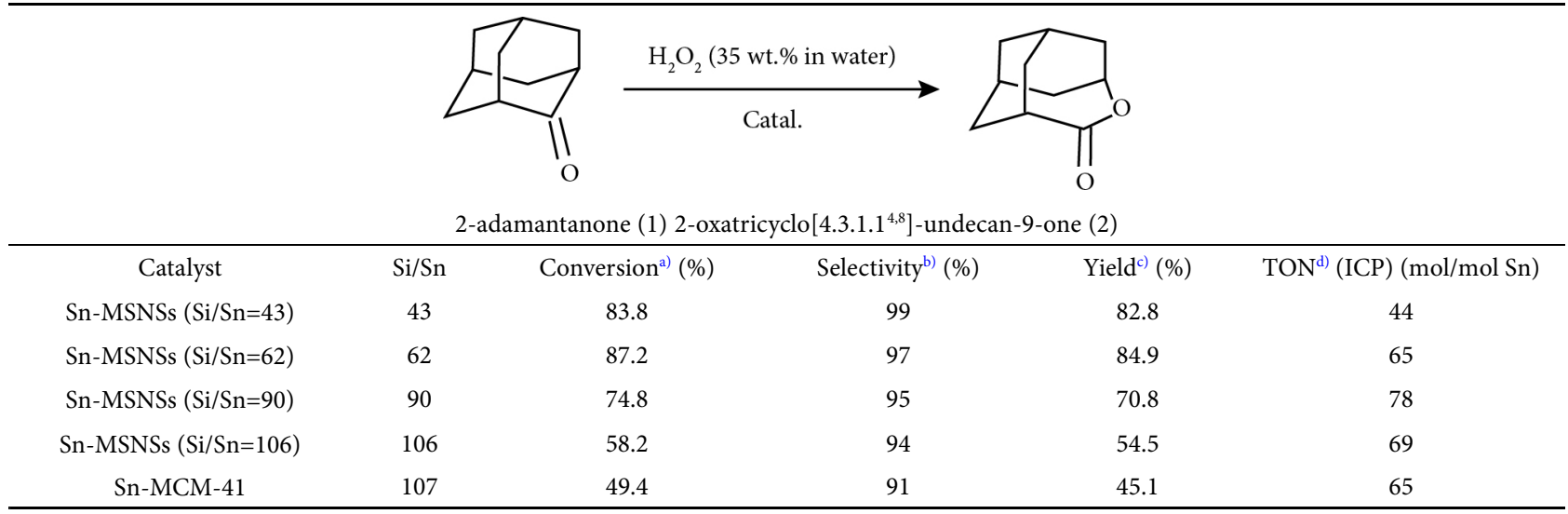

a) Conversion $(\%)=\left[n_{\text {total }}(1)-n_{\text {left }}(1)\right] / n_{\text {total }}(1) \times 100 ;$ b) selectivity $(\%)=n(2) /\left(n_{\text {total }}(1) \times\right.$ conversion $\left.(\%) / 100\right) \times 100 ;$ c $)$ yield $(\%)=n(2) / n_{\text {total }}(1) \times$ 100 ; d) turnover number, (moles of product) $/($ moles of tin centers) at $3 \mathrm{~h}$.

\section{Sn incorporated clay-based catalysts}

Clay minerals are made up of layered silicates with potentials for use as catalysts because of their abundance in nature and their high surface area, sorptive and ion-exchange properties [82]. Especially, solid clay catalysts can be used as catalytically active agents, such as solid acids, as bifunctional or "inert" support, and even as fillers to give solid catalysts with required physical properties [83]. Clays can be divided into smectite-like layered silicates (such as montmorillonite, beidellite, hectorite, and saponite) and layered double hydroxides (such as hydrotalcite, pyroaurite, takovite, and meixnerite). We mainly focus on the Sn 
species incorporated clay catalysts for the BV oxidations by using $\mathrm{H}_{2} \mathrm{O}_{2}$ as oxidant.

\section{Sn-based cationic clay catalysts}

Cationic clays, such as smectites, are widely used in a variety of chemical processes, and BV oxidations have benefited from the use of these catalysts among the various oxidation reactions though they are being replaced by zeolites at an increasing rate, which provide better activity and selectivity. Especially, by incorporating a cation, such as Sn, active Sn-containing cationic clays catalysts for the BV oxidation have been formed. As a kind of cationic clay, palygorskite supported $\mathrm{Sn}$ (II) complexes are efficient in the BV oxidation of cyclic and acyclic ketones with $\mathrm{H}_{2} \mathrm{O}_{2}$ as oxidant $[84,85]$. It should be noted that the procedure for the preparation of the Sn-palygorskite is much simpler than that of Sn-beta zeolites catalysts, which is desirable in large scale application. Furthermore, palygorskite is a biocompatible and environmentally friendly natural mineral abundant in deposits all over the world. In addition, the catalyst can be prepared in large scale and can be recycled.

Except palygorskite, montmorillonite (MMT) is another kind of cationic clay material and is also featured with the characters of biocompatibility and environmentally friendliness, which is constructed of a single octahedral sheet sandwiched between two tetrahedral sheets, with the octahedral sheet sharing the apical oxygen of the tetrahedral sheets (Fig. 12). MMT possesses large specific area and high structural charge (up to $1000 \mathrm{meq} \mathrm{kg}^{-1}$ ), which endow them with excellent adsorption properties [86-88]. MMT supported Sn catalyst Sn-MMT, prepared by ion-exchanging method in the presence of $\mathrm{HCl}$, exhibited an efficient and very cost-effective catalyst for the BV oxidation reactions [89], showing the similar catalytic mechanism to that of the Sn-beta-zeolites [40].

While for the BV oxidation of 2-heptylcyclopentanone to $\delta$-dodecalactone, the tin ion-exchanged bentonite (Sn-bentonite) seems to be a rather efficient and highly selective catalyst, as shown in Table 6, the conversion of 2-heptylcyclopentanone to $\delta$-dodecalactone in high yield $(81 \%)$ could be obtained at the Sn-bentonite catalyst with methanesulfonic acid (MSA) and sodium dodecyl sulfate (SDS) as the additives [90]. The possible reactions are shown in Scheme 2 , in which the cycloketone is coordinated to the Lewis acid tin center to activate the carbonyl group first, similar to Sn-beta-zeolites [40], and then the peroxy acid resulting from the interaction between hydrogen peroxide and MSA attacks the electrophilic carbonyl carbon, thus, leading to the excellent results of the BV oxidation over Sn-bentonite [90]. These Sn incorporated cationic clay materials are prospective catalysts for the wide applications in industry for BV oxidation of ketones for its low cost and facile synthesis.

\section{Sn-based anionic clay catalysts}

Anionic clays as another kind of important catalyst minerals are widely used in the fields such as base catalysis, hydrogenation, polymerization, condensation, alcohol transformation, which show high catalytic activity and good chemoselectivity [91-94]. Anionic clays are also named as "layered double hydroxides" or simply "hydrotalcites", which can be generically formulated as $\left[\mathrm{M}(\mathrm{II})_{1-x} \mathrm{M}(\mathrm{III})_{x}(\mathrm{OH})_{2}\right]^{x+}\left[\mathrm{A}_{n / x}\right]^{n-} \cdot m \mathrm{H}_{2} \mathrm{O}$, where $\mathrm{M}(\mathrm{II})$ and $\mathrm{M}$ (III) are divalent and trivalent metal, respectively, lying at octahedral positions of $\mathrm{Mg}^{2+}$ in brucite-like layers and $A$ is the interlayer anion, which can vary widely in nature and be either inorganic or organic. $x$, which represents the

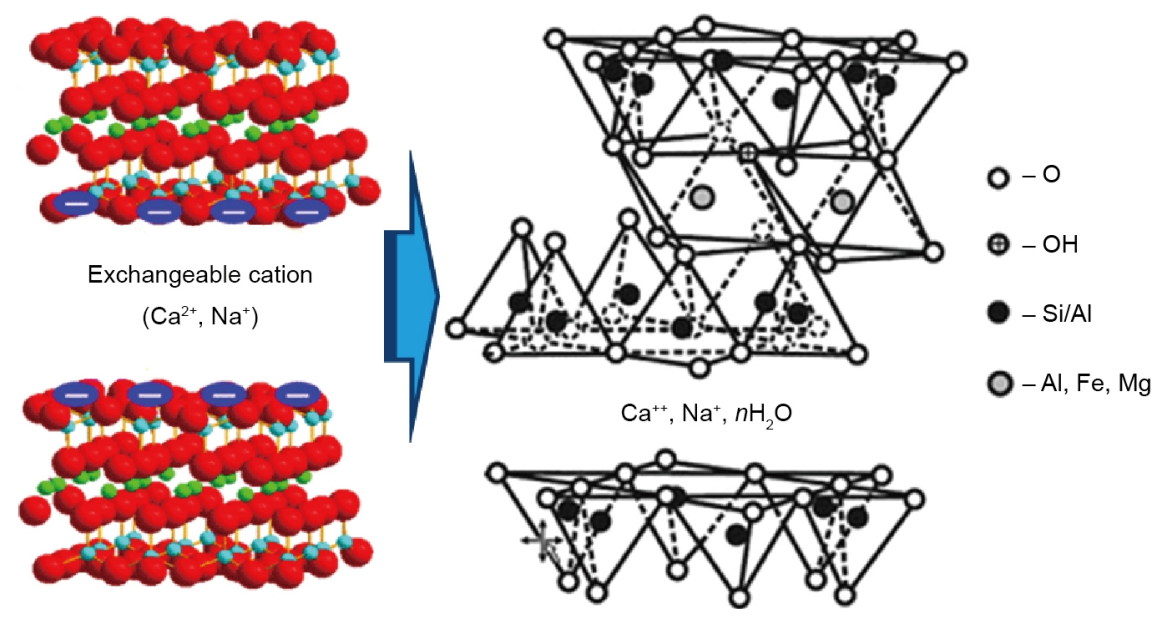

Figure 12 Structure schematics of brucite montmorillonite. 
Table 6 Catalytic performances of Sn-bentonite catalysts for the BV oxidation of 2-heptylcyclopentanone to $\delta$-dodecalactone [90]

\begin{tabular}{|c|c|c|c|c|c|}
\hline Entry & Catalyst & Additive & Time (h) & Conversion $^{\text {a) }}(\%)$ & Yield $^{\text {a) }}(\%)$ \\
\hline 1 & - & - & 24 & 15 & 9 \\
\hline 2 & Sn-bentonite & - & 24 & 38 & 30 \\
\hline 3 & - & MSA & 24 & 21 & 17 \\
\hline 4 & - & MSA, SDS & 24 & 18 & 12 \\
\hline 5 & Sn-bentonite & MSA, SDS & 7 & 95 & 75 \\
\hline $6^{\mathrm{b})}$ & Sn-bentonite & MSA, SDS & 14 & 76 & 52 \\
\hline $7^{\text {c) }}$ & Sn-bentonite & MSA, SDS & 7 & 92 & 69 \\
\hline 8 & Sn-bentonite & MSA, SDS & 7 & 95 & 75 \\
\hline $9^{d)}$ & Sn-bentonite & MSA, SDS & 7 & 83 & 62 \\
\hline 10 & Sn-bentonite & MSA, SDS & 7 & 95 & 75 \\
\hline $11^{\mathrm{e})}$ & Sn-bentonite & MSA, SDS & 7 & 95 & 81 \\
\hline $12^{\mathrm{f})}$ & Sn-bentonite & MSA, SDS & 7 & 83 & 69 \\
\hline $13^{\mathrm{g})}$ & Sn-bentonite & MSA, SDS & 7 & 67 & 53 \\
\hline $12^{\mathrm{h})}$ & Sn-bentonite & MSA, SDS & 7 & 88 & 68 \\
\hline $13^{\mathrm{e})}$ & Sn-bentonite & MSA, SDS & 10 & 99 & 77 \\
\hline $14^{\mathrm{e}), \mathrm{i})}$ & Sn-bentonite & MSA, SDS & 7 & 4 & 2 \\
\hline $15^{\mathrm{e}), \mathrm{i})}$ & Sn-bentonite & MSA, SDS & 7 & 82 & 68 \\
\hline
\end{tabular}

Reaction conditions: 2-heptylcyclopentanone (50 mmol), 35 wt.\% $\mathrm{H}_{2} \mathrm{O}_{2}$ (200 mmol), Sn-bentonite (1.50 g), MSA (2.60 mmol), SDS (0.92 mmol), toluene $10 \mathrm{~mL}, 70^{\circ} \mathrm{C}$. a) Calculated by GC based on the internal standard (nonane); b) MSA (1.04 mmol), SDS (0.37 mmol); c) toluene $20 \mathrm{~mL}$; d) toluene $5 \mathrm{~mL}$; e) 2-heptylcyclopentanone (50 mmol), $35 \mathrm{wt} . \% \mathrm{H}_{2} \mathrm{O}_{2}$ (150 mmol); f) $1^{\text {st }}$ recycled Sn-bentonite; g) $2^{\text {nd }}$ recycled Sn-bentonite; h) 2-heptylcyclopentanone (50 mmol), $35 \mathrm{wt} . \% \mathrm{H}_{2} \mathrm{O}_{2}(100 \mathrm{mmol})$; i) $50^{\circ} \mathrm{C}$; j) $90^{\circ} \mathrm{C}$.

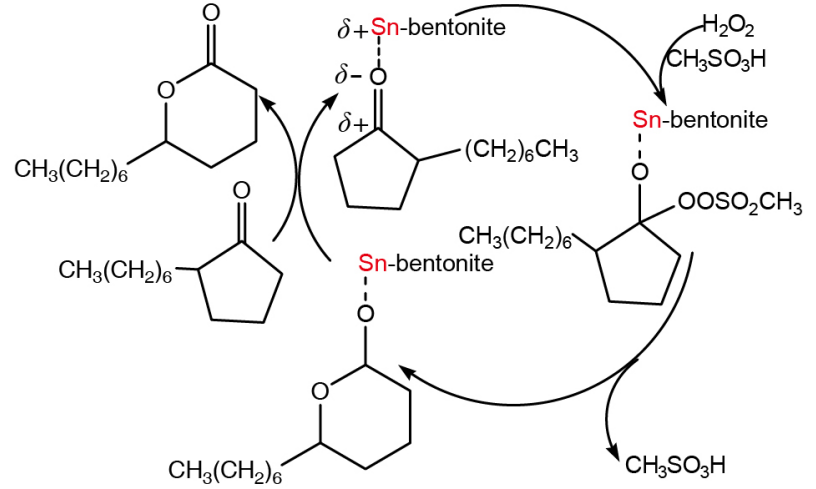

Scheme 2 Possible catalytic pathway for BV oxidation over Sn-bentonite. Reprinted with permission from Ref. [90], Copyright 2015, Springer.

ratio $\mathrm{M}(\mathrm{II}) /[\mathrm{M}(\mathrm{II})+\mathrm{M}(\mathrm{III})]$, usually ranges from 0.17 to $0.33[95,96]$.

The structure of hydrotalcites is similar to brucite, $\mathrm{Mg}(\mathrm{OH})_{2}$, which consists of positively charged layers of double hydroxides and interlayer spacing filled with anions that offset the positive charge of the layers and water molecules (as shown in Fig. 13). Tin oxide catalyst supported on an $\mathrm{Mg} / \mathrm{Al}$ hydrotalcite $(\mathrm{Sn} / \mathrm{HT})$, such as 1.5
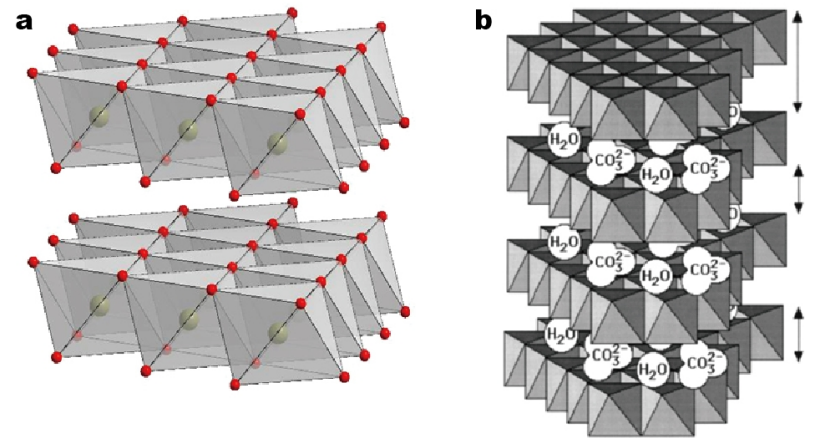

Figure 13 Structure schematics of brucite (a) and Mg/Al hydrotalcite (b).

wt.\% Sn/HT, are active and highly selective for the BV oxidation of a variety of cyclic ketones at $70^{\circ} \mathrm{C}$, and the TONs obtained are generally encouraging by using an $\mathrm{H}_{2} \mathrm{O}_{2}$ /acetonitrile system, since the acetonitrile has a comparatively high dissolving power for both the organic substrate and aqueous $\mathrm{H}_{2} \mathrm{O}_{2}$ as well [97]. The high lactone selectivity can be attributed to the operation of a different mechanism of oxidation from the traditional peroxide catalyzed oxidations. First, acetonitrile is known to activate $\mathrm{H}_{2} \mathrm{O}_{2}$ by forming a perhydroxyl anion $\left(\mathrm{OOH}^{-}\right)$, 
which nucleophilically attacks the nitrile group to generate a peroxycarboximidic acid intermediate $[98,99]$. The intermediate is an effective oxygen transfer agent. In the meantime, the carbonyl group of the ketone is activated by coordinating to the Lewis acid center $(\mathrm{Sn})$ on the catalyst, in which the electrophilicity of carbonyl carbon is increased. This is followed by a nucleophilic attack by the active peroxide species (peroxycarboximidic acid in this case) to form a "Criegee" adduct which rearranges to give a lactone. The second step of the mechanism is similar with the oxidation mechanism for the reaction over Sn-beta zeolite catalyst reported by Corma et al. [40]. However, the catalyst is apparently not active for the oxidation of aliphatic and acyclic ketones, such as 2-hexanone and acetophenone, because the methyl group has the lowest migrating mobility [100]. In addition, as hydrotalcite is also an excellent epoxidation catalyst $[98,99]$, thus, the $\mathrm{Sn} / \mathrm{HT}$ catalyst system is not selective for the lactone formation in the case of olefinic ketones.

Among the hydrotalcites of variable metal composition, such as $\mathrm{Mg} / \mathrm{Al}, \mathrm{Mg} / \mathrm{Al} / \mathrm{Sn}$ and $\mathrm{Mg} / \mathrm{Al} / \mathrm{Zr}$, the tin-containing catalyst were the most active and provided better results for the BV oxidation of cyclohexanone with $\mathrm{H}_{2} \mathrm{O}_{2}$ as oxidant and benzonitrile as solvent [101]. This is due to the different two-step mechanism from that reported by Pillai et al. [97], $\mathrm{H}_{2} \mathrm{O}_{2}$ firstly attacks a Brønsted ba- sic site at the catalyst surface to form a hydroperoxide species, which subsequently attacks benzonitrile to form a peroxycarboxymidic intermediate. In the second step, the previous formed intermediate attacks a cyclohexanone molecule adsorbed at Lewis acid site of the Sn/HT catalyst to form an intermediate resembling the "Criegee" adduct in homogeneous catalytic processes. Finally, the intermediate undergoes rearrangement to the corresponding lactone [102]. Though Sn-containing hydrotalcite catalyst is effective for the BV oxidation, the preparation method may lead to a different catalytic performance. Sn-hydrotalcite-like catalyst prepared by ion-exchanging method exhibits better catalytic performance for the liquid phase $\mathrm{BV}$ oxidation of admantonone than the catalysts prepared by direct synthesis or grafting approaches when using $\mathrm{H}_{2} \mathrm{O}_{2}$ as the oxidant and acetonitrile as the solvent [103].

Recently, Hara et al. [104] successfully intercalated Sn species into lithium taeniolite ( $\mathrm{Li} / \mathrm{TN})$ to form a novel clay catalyst $(\mathrm{Sn}(x) / \mathrm{TN})$ by a conventional cation-exchange method, and the kind of $\operatorname{Sn}(x) / \mathrm{TN}$ catalysts showed extremely high performance in $\mathrm{BV}$ oxidation of various cyclic ketones with $\mathrm{H}_{2} \mathrm{O}_{2}$ as oxidant as shown in Table 7, e.g., the conversion rate of $\mathrm{BV}$ oxidation cyclopentanone can reach at $100 \%$ with a target product selectivity of $>99 \%$, and the value for adamantanone is $98 \%$ with a selectivity of $>99 \%$. The highly dispersed isolated $\mathrm{Sn}^{\mathrm{IV}}$ species in the $\mathrm{TN}$

Table 7 BV oxidations of ketones by using $\operatorname{Sn}(0.77) / \mathrm{TN}$ as catalyst ${ }^{\mathrm{a})}$ [104]

\begin{tabular}{|c|c|c|c|c|c|}
\hline Entry & Substrate & Time $(\mathrm{h})$ & Product & Conversio $^{\text {b) }}(\%)$ & Yield $^{\text {b) }}(\%)$ \\
\hline 1 & & 2 & & 100 & $>99(89)$ \\
\hline $2^{\text {c) }}$ & & 2 & & 99 & 98 \\
\hline $3^{\text {d) }}$ & & 2 & & 97 & 97 \\
\hline 4 & & 10 & & 100 & $>99(78)$ \\
\hline 5 & & 6 & & 98 & $98(93)$ \\
\hline 6 & & 6 & & 98 & $>99(81)$ \\
\hline 7 & & 6 & & 77 & 72 \\
\hline
\end{tabular}

a) Substrate $(0.5 \mathrm{mmol}), \mathrm{Sn}(0.77) / \mathrm{TN}$ catalyst $(0.05 \mathrm{~g}, \mathrm{Sn}: 7.7 \mathrm{~mol} \%), 1,2-\mathrm{DCE}(1.5 \mathrm{~mL}), 30 \mathrm{wt} \% \mathrm{H}_{2} \mathrm{O}_{2}(2$ eq. relative to the ketone), reflux; b) determined by GC using an internal standard technique. Values in parentheses were isolated yields; c) $1^{\text {st }} \mathrm{cycle}$; d) $2^{\text {nd }}$ cycle. 
interlayer has proven to be active species for selective and environmentally benign BV oxidation. It is satisfactory that no Sn leaching was observed during the oxidations, and the catalyst was recyclable.

Sn incorporated clay catalysts would be prospective in the application of BV oxidation of ketone or cyclic ketone owing to their high catalytic activity, good chemoselectivity and mild catalytic condition, though they are less active in the BV oxidation of aliphatic and acyclic ketones. Especially, the synthetic procedure of the Sn-based clay catalysts is simple and facile, which is desirable in broad catalytic applications. More importantly, the Sn-based clay catalysts are usually cost-effective, biocompatible and environmentally friendly, which are encouraging if used as catalysts for BV oxidations.

\section{$\mathrm{MO}-\mathrm{SnO}_{2}$ metal oxide nanocomposite catalysts}

As important solid acids, transition metal oxides are currently attracting considerable attention due to their unique properties and broad range of potential applications. These materials have been used in the isomerization of alkanes and other petrochemical processes such as alkylation of aromatics and hydrocarbon cracking [105]. Monometallic oxides such as $\mathrm{MgO}$ [106], $\mathrm{SnO}_{2}$ [107], $\mathrm{WO}_{3}$ [108], $\mathrm{ZrO}_{2}$ [109], $\mathrm{TiO}_{2}$ [110], $\mathrm{Al}_{2} \mathrm{O}_{3}$ [111], $\mathrm{Nb}_{2} \mathrm{O}_{5}$ [112], $\mathrm{Ta}_{2} \mathrm{O}_{5}$ [113], and bimetallic oxides such as $\mathrm{Nb}-\mathrm{Ta}$ oxides [114,115], $\mathrm{Mg}$ - $\mathrm{Ta}$ oxides [116], $\mathrm{Nb}-\mathrm{W}$ oxides [117], $\mathrm{Sn}-\mathrm{W}$ oxides [118], $\mathrm{Zr}-\mathrm{W}$ oxides [119], and $\mathrm{WO}_{3}-\mathrm{TiO}_{2}[120,121]$ have been extensively explored. The transition-metal centers in the inorganic frameworks of porous structures also possess variable oxidation states and empty $\mathrm{d}$-orbitals, which allow electron transfer to occur between the reactants and active sites during the catalytic process [122].

Magnesium based oxides, such as $\mathrm{MgO}, \mathrm{Mg}(\mathrm{OH})_{2}$, HT, exhibit high catalytic activity for BV oxidations [123-125]. By a co-precipitation method, bimetal oxide including $\mathrm{MgO} / \mathrm{SnO}_{2}, \mathrm{MgO} / \mathrm{Al}_{2} \mathrm{O}_{3}, \mathrm{MgO} / \mathrm{La}_{2} \mathrm{O}_{3}, \mathrm{MgO} / \mathrm{TiO}_{2}$, $\mathrm{MgO} / \mathrm{ZnO}$, etc. can be successfully prepared. Among these oxides, $\mathrm{MgO} / \mathrm{SnO}_{2}$ showed the most excellent catalytic performance in the BV oxidation of cyclohexanone to $\varepsilon$-caprolactone with aqueous hydrogen peroxide as an oxidant [126]. Especially, under optimal reaction conditions, the as-prepared $\mathrm{MgO} / \mathrm{SnO}_{2}$ catalyst with the $\mathrm{Mg} / \mathrm{Sn}$ molar ratio of 7:3 presented a cyclohexanone conversion rate of $90.5 \%$ and caprolactone selectivity of $100 \%$. The catalytic mechanism of $\mathrm{MgO} / \mathrm{SnO}_{2}$ is much different from that reported by Corma et al. [40]. For $\mathrm{MgO} / \mathrm{SnO}_{2}$ catalyst, $\mathrm{H}_{2} \mathrm{O}_{2}$ firstly attack the Brønsted basic site on the catalyst surface resulting in the formation of peroxide intermediate, and the formed peroxide intermediate is unstable and will react with benzonitrile to form intermediate similar with peracid, which is the same as the mechanism reported by Ruiz et al. [123]; secondly, as reported by Corma et al. [40], the coordination of cyclohexanone to the Lewis acid of Sn site results in the enhanced electrophilicity of carbonyl carbon, which facilitates the nucleophilic attack by activated $\mathrm{H}_{2} \mathrm{O}_{2}$. Thus, the bimetal oxides $\mathrm{MgO} / \mathrm{SnO}_{2}$ shows much higher catalytic activity than the single $\mathrm{MgO}$ or single $\mathrm{SnO}_{2}$.

$\mathrm{Sn} / \mathrm{W}$ mixed transition-metal oxides prepared by calcining corresponding $\mathrm{Sn} / \mathrm{W}$ hydroxide precursors at different temperatures could act as effective heterogeneous catalysts for the BV oxidation of ketones [127], and many ketones such as adamantanone, cyclopentanone, cyclohexanone, as well as benzyl alcohol were transformed into the corresponding products with high conversion rates of $65 \%-100 \%$ and high selectivities of $82 \%-100 \%$. Moreover, the catalysts can be easily separated from the reaction mixtures and reused for at least five cycles without significant loss of activity as known from the data shown in Table 8 . Shortly afterwards, Fe-doped $\mathrm{SO}_{4}{ }^{2-} / \mathrm{SnO}_{2}$ (STF, with the $\mathrm{Fe} / \mathrm{Sn}$ molar ratio of 0.5 ) solid acid catalysts were proved to be efficient and stable catalysts for the BV oxidation of cyclic ketones including adamantanone, cyclopentanone, cyclohexanone and benzyl alcohol with the corresponding conversion rates and target product selectivities of $77 \%-99 \%$ and $85 \%-99 \%$, respectively [128]. Besides bimetal oxides, ternary metal oxides, such as $\mathrm{Mg} / \mathrm{Sn} / \mathrm{W}$ mixed oxides prepared via co-precipitation were found to be capable of providing the highest yield of $\varepsilon$-caprolactone when using a mixture of $50 \%$ hydrogen peroxide and acetic acid as co-oxidant [129]. For the same BV oxidation of cyclohexanone, Fe-Sn-O ternary metal oxide catalyst with a tetragonal structure showed a $\varepsilon$-caprolactone yield as high as $98.8 \%$, and without any major decline in catalytic activity even cycled for five times [130].

Table 8 Recycling performances of Sn/W-2-800 catalyst in the BV oxidation of 2-adamantanone [127]

\begin{tabular}{cccccc}
\hline Entry & 1 & 2 & 3 & 4 & 5 \\
\hline Conversion (\%) & 100 & 100 & 99 & 97 & 93 \\
Selectivity (\%) & 100 & 99 & 99 & 99 & 97 \\
\hline
\end{tabular}

Reaction conditions: 2 -adamantanone $0.1 \mathrm{mmol}$, catalyst $6 \mathrm{mg}, 30 \%$ $\mathrm{H}_{2} \mathrm{O}_{2} 2.0$ eq., 1,2-dichloroethane $3 \mathrm{~mL}, 10 \mathrm{~h}, 75^{\circ} \mathrm{C}$. Conversion rate and selectivity were determined by GC analysis. 


\section{Polymer based Sn catalysts}

Organic polymer-supported reagents have been found widespread utility in organic synthesis [131]. The use of polymer-bound complexes in catalysis dates from about 30 years ago for meeting the need of separating soluble catalysts from the reaction mixtures [132,133]. For example, aminomethyl polystyrene resin-supported tin complex (PS-Sn) catalyst is an active and selective catalyst for the BV oxidation of cyclic and acyclic ketones including 2-adamantanone, 2-methylcyclohexanone, cyclohexanone, 2-tert-butylcyclohexanone, 4-tert-butylcyclohexanone, 4-methylcyclohexanone, 3-methyl-2-pentanone, 4-methyl-2-pentanone, and cyclopentanone using 30\% $\mathrm{H}_{2} \mathrm{O}_{2}$ as oxidant. This new catalytic system with $\mathrm{Sn}$ content of $1.28 \mathrm{wt} . \%$ can be prepared in a simple procedure (shown in Scheme 3) and permits recycled use [134]. Through a solid phase synthesis method, dendritic Sn complexes can also be incorporated into chloromethyl polystyrene to obtain promising BV oxidation catalysts (P-PAMAM-HBA (1.0G)-Sn(II)), which exhibit high conversion rate of $63 \%-99 \%$ and $100 \%$ target product selectivity for the BV oxidation of cyclic and acyclic ketones [135]. Moreover, the catalysts can be prepared in a simple and large scale

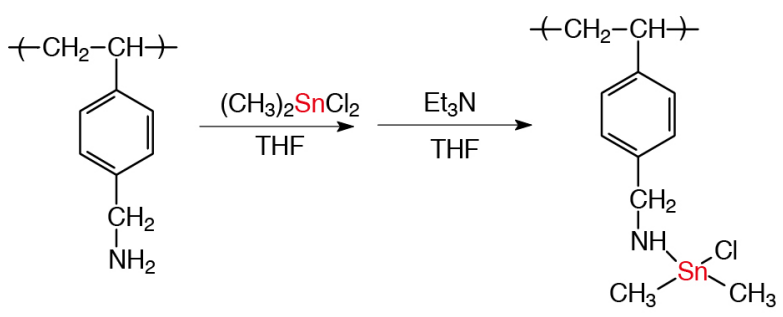

Scheme 3 The synthesis scheme of aminomethyl polystyrene resin-supported tin complex (PS-Sn) catalyst. Reprinted with permission from Ref. [134], Copyright 2006, Elsevier.

manner without the utilization of any expensive materials and can be recycled as heterogeneous catalysts.

Shortly after this report, Li et al. [136] prepared another kind of dendritic Sn complex catalyst by using cellulose as support through employing a solid phase synthetic methodology as shown in Schemes 4 and 5, and the synthesized catalyst, P-PAMAM-HBA (2.0G)-Sn (II), is proved to be efficient for the BV oxidation of the cyclic ketones and acyclic ketones, such as 2-adamantanone, cyclohexanone, 4-methylcyclohexanone, 4-tert-butylcyclohexanone, 3-methyl-2-pentanone, 4-methyl-2-pentanone and cyclopentanone with hydrogen peroxide as oxidant.

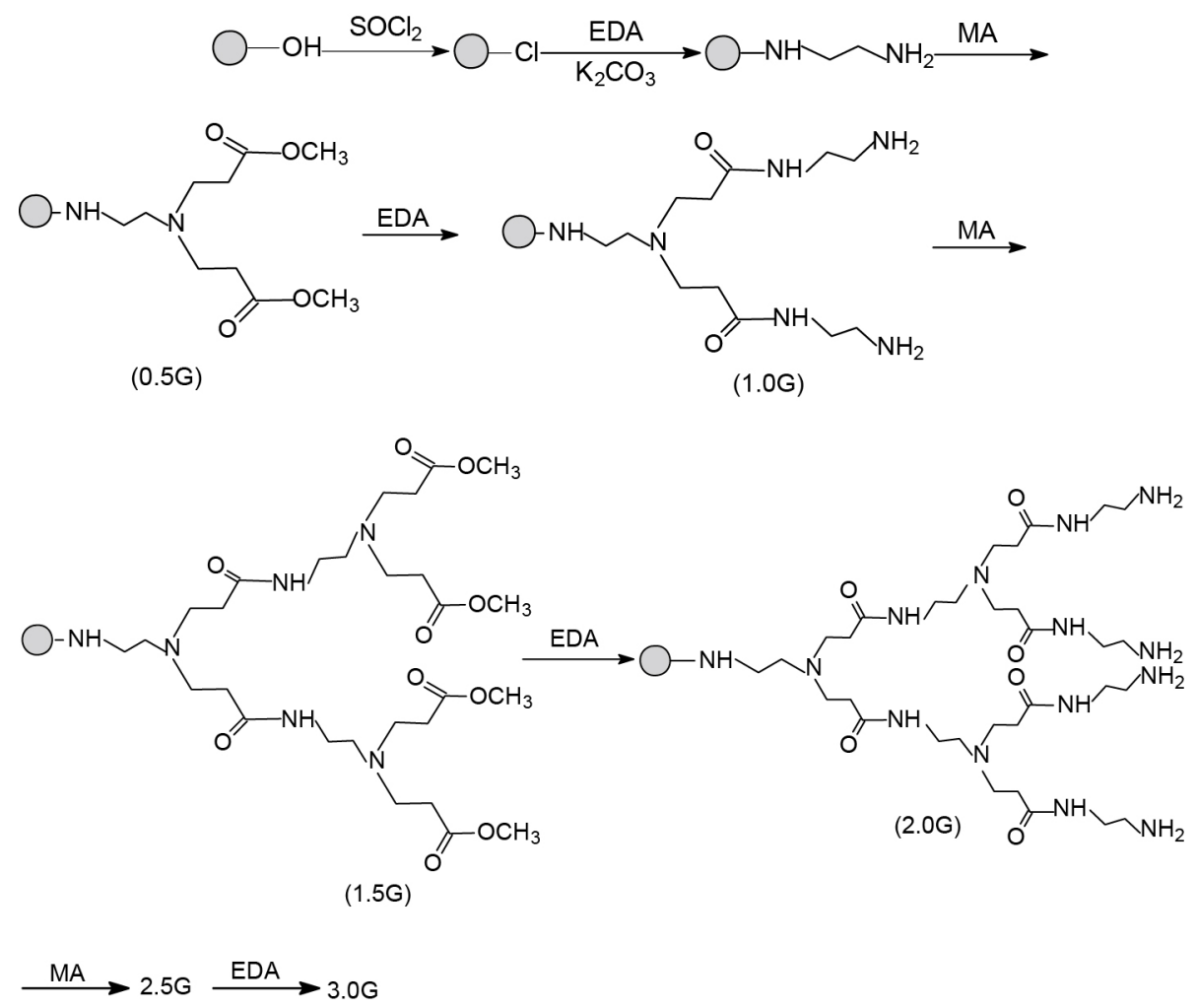

Scheme 4 The procedure for the preparation of the polymer-supported dendrimers. Reprinted with permission from Ref. [136], Copyright 2007, Elsevier. 

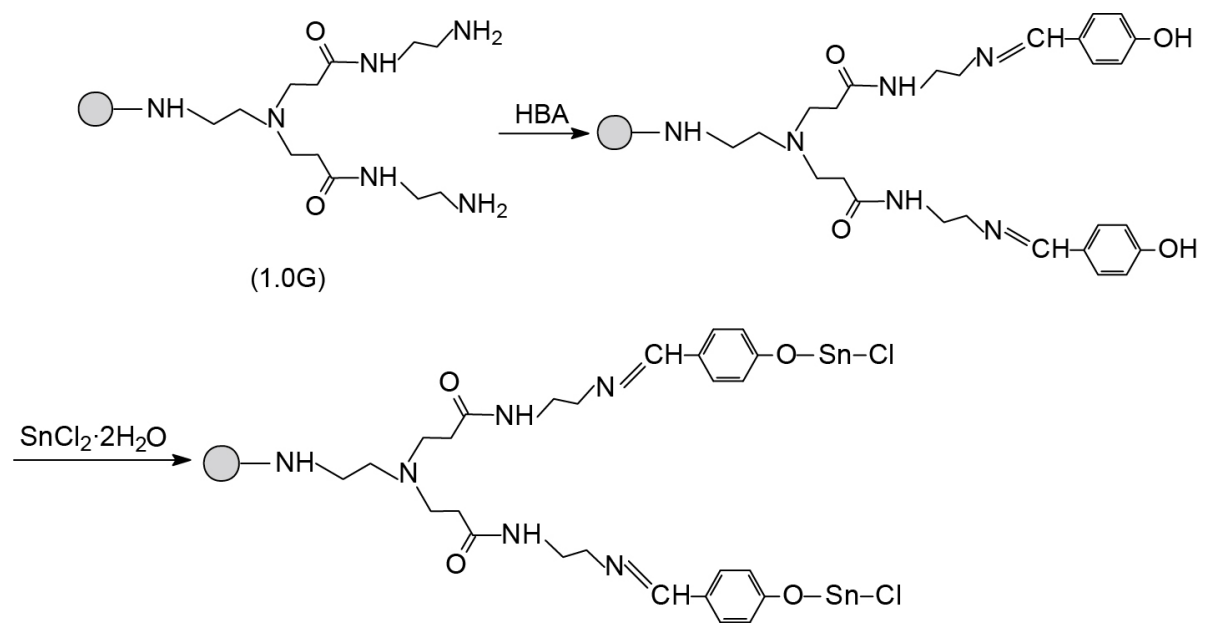

Scheme 5 The procedure for the preparation of the ligand of first generation. Reprinted with permission from Ref. [136], Copyright 2007, Elsevier.

Especially, it is enviable that the cellulose-supported dendritic Sn complexes afford the corresponding lactones or esters with the conversion rate of $70 \%-99 \%$ and the product selectivity of $100 \%$. Moreover, the catalyst P-PAMAMHBA (2.0G)-Sn (II) can be recycled for several times without any significant decline in catalytic activity. For this catalyst, the mechanism is analogous to the mechanism reported by Corma et al. [40]. Also, the dendritic Sn complexes can be incorporated into chitosan, which also exhibit promising catalytic performance for the $\mathrm{BV}$ oxidation of ketones in the presence of $\mathrm{H}_{2} \mathrm{O}_{2}$. Notably, the chitosan-supported dendritic Sn complex catalysts can be prepared in a simple and large scale manner with low-cost raw materials and also can be recycled [137].

Though use of $\mathrm{H}_{2} \mathrm{O}_{2}$ is a "green" process as water is the byproduct of this oxidation reaction, the main challenges to this process are the compatibility of solvent with aqueous $\mathrm{H}_{2} \mathrm{O}_{2}$ and finding the right catalyst which could activate peroxide in the presence of water. To overcome this problem, a new family of porous and layered Sn(IV) phenylphosphonates (SnPP) with high surface areas and $1-2 \mathrm{~nm}$ in pore diameters were developed $[138,139]$, and these materials have been found to be extremely active for $\mathrm{BV}$ reaction of aromatic aldehydes using $30 \%$ aqueous $\mathrm{H}_{2} \mathrm{O}_{2}$ solution. When the SnPP catalysts were used to catalyze the BV oxidation on 4-methoxybenzaldehyde, a maximum conversion rate of $88 \%$ was observed over $\mathrm{Sn}(\mathrm{IV})\left(\mathrm{O}_{3} \mathrm{PC}_{6} \mathrm{H}_{4}-\mathrm{C}_{6} \mathrm{H}_{4} \mathrm{PO}_{3}\right)$ (SnPP-A) [140]. Table 9 gives the catalytic activity of different $\mathrm{Sn}$ catalysts for the BV oxidation of 4-methoxybenzaldehyde. It can be seen that the catalyst SnPP-A shows conversion rate of $98 \%$ and target selectivity of $100 \%$, which are much higher than those of Sn-beta zeolite with conversion rate of $58 \%$ and target selectivity of $86 \%$. Though the amount of Sn contained in SnPP-A is much higher than in the other Sn systems, SnPP-A exhibits much higher catalytic activity compared to other heterogeneous catalysts reported in the literatures [140].

The most fascinating part of the SnPP-A catalyst is that the $\mathrm{BV}$ reaction proceeds more efficiently in the absence of any organic solvents. This is a great progress in the BV oxidation by using $\mathrm{H}_{2} \mathrm{O}_{2}$ as oxidant, because various products can be formed depending on the catalyst and the solvent used in the BV oxidations of aromatic aldehydes.

\section{CATALYTIC MECHANISM OF Sn-BASED CATALYSTS FOR BV OXIDATION BY USING $\mathrm{H}_{2} \mathrm{O}_{2}$}

Generally, the catalytic mechanism of the Sn-based catalysts for the catalytic $\mathrm{BV}$ oxidation by using $\mathrm{H}_{2} \mathrm{O}_{2}$ as oxidant

Table 9 Comparisons of catalytic activity among three kinds of Sn catalysts in the BV oxidation of 4-methoxybenzaldehyde

\begin{tabular}{|c|c|c|c|c|}
\hline Catalyst & Sn (wt.\%) & Conversion (\%) & Selectivity (phenol \%) & Comments \\
\hline Beta zeolite $\mathrm{SnO}_{2}$ & $\sim 2$ & 56 & 46 & Acetonitrile $50 \% \mathrm{H}_{2} \mathrm{O}_{2}[41]$ \\
\hline Sn-beta Zeolite & $\sim 2$ & 58 & 86 & Toluene $35 \% \mathrm{H}_{2} \mathrm{O}_{2}[43]$ \\
\hline SnPP-A & 24.5 & 98 & 100 & No solvent $30 \% \mathrm{H}_{2} \mathrm{O}_{2}[140]$ \\
\hline
\end{tabular}

Reaction conditions: $0.05 \mathrm{~g}$ catalyst $\left({ }^{*} 0.025 \mathrm{~g}\right.$ catalyst), $80^{\circ} \mathrm{C}, 7 \mathrm{~h}, 3.7 \mathrm{mmol}$ of aldehyde and $4.5 \mathrm{mmol}^{\circ} \mathrm{H}_{2} \mathrm{O}_{2}$. 
can be mainly divided into two catalogues, one is the activation of ketone carbonyl by catalysts facilitating the nucleophilicity attack by $\mathrm{H}_{2} \mathrm{O}_{2}$, and the other is the co-activation of both $\mathrm{H}_{2} \mathrm{O}_{2}$ and ketone substrate, which will be discussed specifically as following.

\section{Ketone carbonyl activation for increased carbonyl carbon electrophilicity}

BV oxidation involves two principal steps: (1) addition of the hydrogen peroxide oxidant and the ketone substrate to form the "Criegee" intermediate and (2) BV rearrangement of the Criegee intermediate to the ester product. The Gibbs activation barriers for the addition and rearrangement steps in the non-catalyzed BV oxidation have been reported to be 39.8 and $41.7 \mathrm{kcal} \mathrm{mol}^{-1}$, respectively $[141,142]$, which makes the reaction difficult to proceed without catalyst. By employing specific Sn-containing catalysts, the Gibbs activation barriers for the addition and rearrangement steps will be much reduced due to the activation of ketone carbonyl by the Lewis acid of Sn sites on the catalysts. Specifically, as shown in Scheme 6, the ketone carbonyl molecule will firstly coordinate to the Sn site on the catalyst and then is activated by the Lewis acid site of Sn species, resulting in the increased electrophilicity of carbonyl carbon. Subsequently, the electrophilicity enhancement of the carbonyl carbon facilitates the nucleophilic attack by a $\mathrm{H}_{2} \mathrm{O}_{2}$ molecule to form a "Criegee" intermediate. Finally, the ester is formed following the intermediate rearrangement. This catalytic mechanism makes the BV oxidation of ketones possess not only high conversion rate but also high chemoselectivity. As a representative, the Sn-beta-zeolite catalysts follow this type catalytic mechanism which was firstly reported by Corma et al. [40], so does Sn-MFI-ns [46], Sn substituted de- laminated zeolites (Sn-DZ-1) [48], and the Sn-based $\mathrm{NaY}$ zeolites [50]. In addition, this type of catalytic mechanism is also applicable for Sn-based mesoporous catalysts such as Sn-MCM-41 [59,60], Sn-SBA-15 [64], Sn-MCM-48 [65], Sn-SBA-16 [71], Sn-MWW [77]. Sn-based cationic clay catalysts such as Sn-palygorskite [84,85], Sn-MMT [89], Sn-bentonite [90], and Sn-based polymer catalysts such as aminomethyl polystyrene resin supported tin complex (PS-Sn) [134], chloromethyl polystyrene supported dendritic Sn complexes catalyst (P-PAMAM-HBA (1.0G)-Sn(II)) [135], cellulose supported dendritic Sn complexes catalyst (P-PAMAM-HBA (2.0G)-Sn (II)) [136], chitosan supported dendritic Sn complexes [137], porous Sn(Iv) phenylphosphonates (SnPP) [140].

The homogeneous catalyst, Sn-based FBS catalyst, also follows this type of catalytic mechanism, such as tin(IV) bis(perfluorooctanesulfonyl)amide [31,32]. This is because that the high amount of fluorine in the $-\mathrm{N}\left(\mathrm{SO}_{2} \mathrm{C}_{8} \mathrm{~F}_{17}\right)_{24}$ ligand endows the catalyst with enhanced electrophilicity and the electropositivity of Sn metal active center as well, which in turn results in significantly elevated electrophilicity of carbonyl carbon atom of a ketone molecule once coordinated to the tin(IV) bis(perfluorooctanesulfonyl)amide catalyst, thus the nucleophilic attack by $\mathrm{H}_{2} \mathrm{O}_{2}$ will be intensified, leading to the accelerated $\mathrm{BV}$ oxidation of ketones.

\section{Co-activation of oxidant $\mathrm{H}_{2} \mathrm{O}_{2}$ and carbonyl of ketone}

In this type catalytic mechanism, not only the carbonyl carbon of ketone molecule, the oxidant $\mathrm{H}_{2} \mathrm{O}_{2}$ is also activated by solvent or catalyst. In principle, $\mathrm{H}_{2} \mathrm{O}_{2}$ may be basically activated in three ways [143], (1) hydroxy $\left(\mathrm{OH}^{-}\right)$ and hydroperoxy $\left(\mathrm{HOO}^{-}\right)$radicals may be generated via a Haber-Weiss mechanistic scheme in the presence of metal

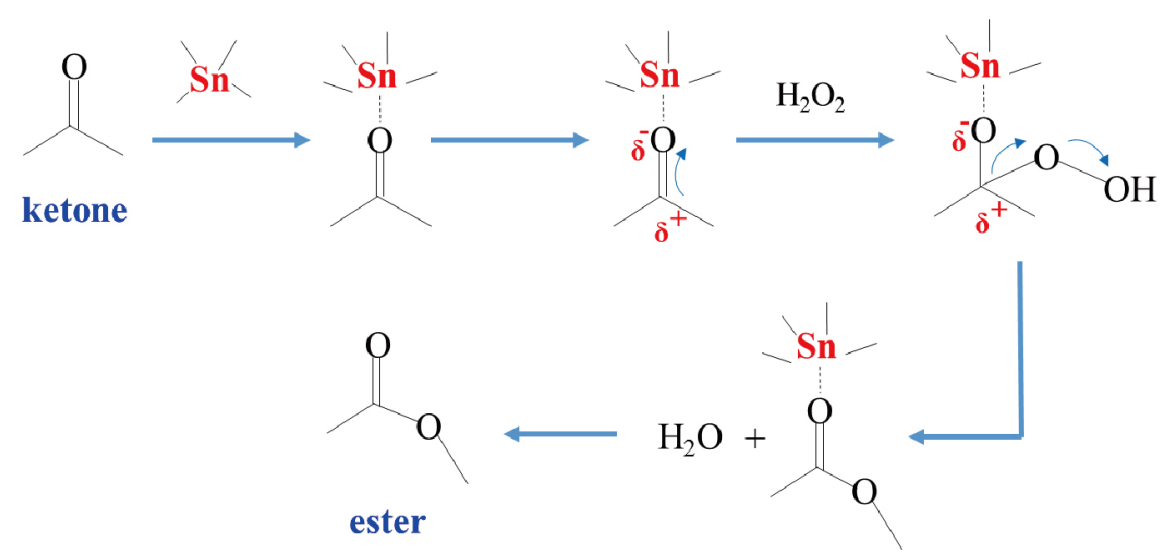

Scheme 6 The catalytic mechanism of ketone activation by Sn-based catalyst during the BV oxidation: ketone carbonyl is activated by coordinating to a Lewis acidic $\mathrm{Sn}$ site resulting in the electrophilicity enhancement of carbonyl carbon, which facilitates the nucleophilic attack by a $\mathrm{H}_{2} \mathrm{O}_{2}$ molecule. 
compound catalysts. However, these radicals usually lead to nonselective transformations of organic substrates; (2) strong $\mathrm{HOO}^{-}$nucleophile can be well created under basic conditions, which is active for the epoxidation of electrophilic alkenes such as $\beta$-unsaturated ketones or carboxylic acid derivatives; (3) heterolytic oxidation, which is probably the most important synthetic application of $\mathrm{H}_{2} \mathrm{O}_{2}$ in the area of as in the epoxidation of alkenes. In the case of Sn-based catalysts for BV oxidation of ketones, $\mathrm{H}_{2} \mathrm{O}_{2}$ can be most probably activated via the first and second pathway.

During the BV oxidation of ketones, the activations of $\mathrm{H}_{2} \mathrm{O}_{2}$ and carbonyl of ketone can be achieved in the following two routes. In route (I), $\mathrm{H}_{2} \mathrm{O}_{2}$ is activated by the organic solvent used (such as acetonitrile) or additive (such as methanesulfonic acid) as shown in Scheme 7a, to form a hydroperoxy $\left(\mathrm{HOO}^{-}\right)$, which is responsible for the nucleophilic attack on nitrile to generate a peroxycarboximidic acid intermediate $[98,99]$. Such an intermediate is an efficient oxygen transfer agent ready to nucleophilically attack carbonyl carbon. Meanwhile, the carbonyl group on ketone is activated by coordinating to the Lewis acidic Sn center on the catalyst forming an electrophilic carbonyl carbon as shown in Scheme 7b, which further facilitates the nucleophilic attack by the active peroxide species (peroxycarboximidic acid in this case) to form a "Criegee" adduct. Finally, the adduct intermediate rearranges to give lactone. Thus, a different mechanism of $\mathrm{BV}$ oxidation from the traditional peroxide catalyzed oxidation mechanism can be outlined, in which actually the second step of carbonyl carbon activation is principally the same as the BV oxidation mechanism over Sn-beta-zeolite catalyst reported by Corma et al. [40]. The catalytic mechanism of Sn-based cationic clay catalysts such as Sn-bentonite catalyst [90] and Sn-based anionic clay catalysts such as Sn-doped hydrotalcite $(\mathrm{Sn} / \mathrm{HT})$ catalyst [97], for BV oxidation of ketones follows this route (I) including two activation steps.
The route (II) of the co-activation is that both $\mathrm{H}_{2} \mathrm{O}_{2}$ and carbonyl of ketone are activated by the Sn-based catalysts. In the absence of solvent coordination, tin-based catalyst activates hydrogen peroxide to produce a tin hydroperoxo $(\mathrm{SnOOH})$ intermediate with a moderate Gibbs activation barrier of $15.4 \mathrm{kcal} \mathrm{mol}^{-1}[141,142]$. Water molecules' coordinating to the tin active site facilitates the proton transfer and lower the Gibbs activation barrier for tin hydroperoxo intermediate formation by 3-7 kcal mol${ }^{-1}$, further favoring the activation of $\mathrm{H}_{2} \mathrm{O}_{2}$ by $\mathrm{Sn}$-based catalyst $[141,142]$. Specifically, as shown in Scheme 8a, hydrogen peroxide firstly attacks a Brønsted basic site at the Sn-based catalyst surface to form a metal hydroperoxide ( $\mathrm{SnOOH}$ ), which is active species and subsequently attacks solvent, such as benzonitrile, to form a peroxycarboxymidic intermediate [101]. Secondly, the ketone molecule coordinates to the Lewis acid site of the Sn-based catalyst, which activates the carbonyl of ketone, resulting in the enhanced electrophilicity of the carbonyl carbon (Scheme 8b), which in turn intensifies the nucleophilic attack by previously formed peroxycarboxymidic intermediate to form an intermediate resembling the "Criegee" adduct in homogeneous catalytic processes. Finally, the intermediate undergoes rearrangement to the corresponding lactone product. In this route, the Sn-based catalyst plays a bifunctional role in activating both $\mathrm{H}_{2} \mathrm{O}_{2}$ molecules and carbonyl group of ketone. The catalytic process in the BV oxidation over a number of Sn-based catalysts, for example, Sn-incorporated anionic clay catalysts, such as $\mathrm{Sn}$-doped hydrotalcite $(\mathrm{Sn} / \mathrm{HT})$ when using $\mathrm{H}_{2} \mathrm{O}_{2}$ as oxidant and benzonitrile as solvent [97], and $\mathrm{MO}-\mathrm{SnO}_{2}$ metal oxide catalysts, such as $\mathrm{MgO} / \mathrm{SnO}_{2}$ [126], follow the route (II) of the co-activation of $\mathrm{H}_{2} \mathrm{O}_{2}$ molecules and carbonyl group of ketone.

In fact, the Sn-based zeolite beta is also bifunctional because of the existence of $\mathrm{Sn}-\mathrm{OH}$ specie in the form of $\mathrm{Sn}\left(\mathrm{OSiH}_{3}\right)_{3} \mathrm{OH}$ cluster. Both the quantum-chemical results and the kinetic study indicate that the catalytically active

a<smiles>CC=NC(=O)OOOC#N</smiles>

(a) intermediate

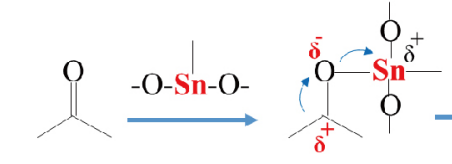

ketone (a)

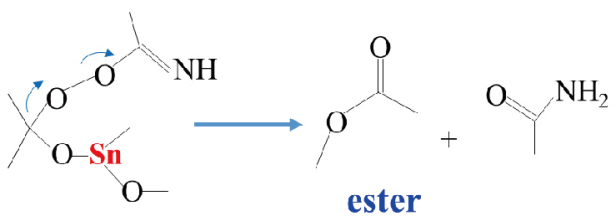

Scheme 7 The catalytic mechanism of $\mathrm{H}_{2} \mathrm{O}_{2}$ and carbonyl group co-activation via route $\mathrm{I}: \mathrm{H}_{2} \mathrm{O}_{2}$ is activated by solvent and ketone activated by Sn-based catalyst during Baeyer-Villiger oxidation. 


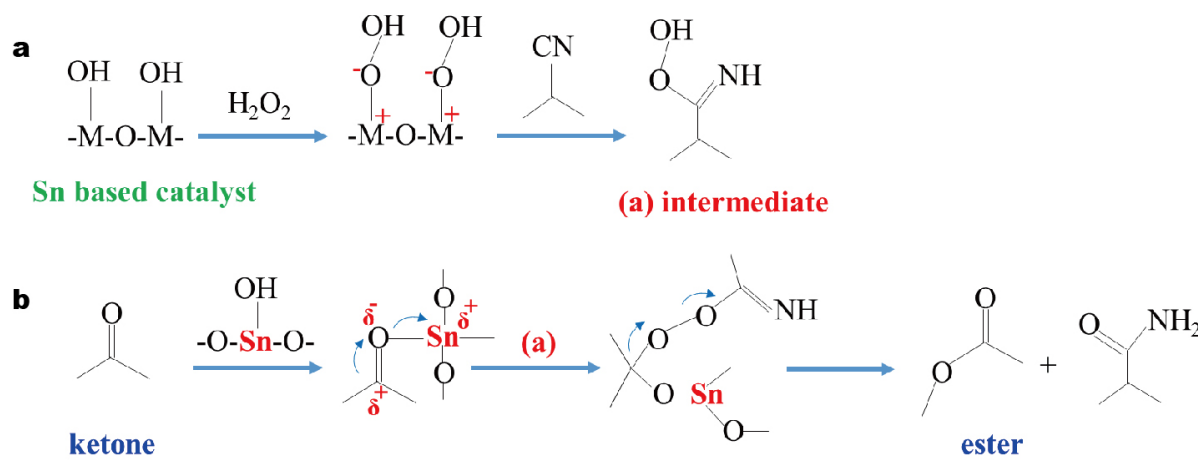

Scheme 8 The catalytic mechanism of $\mathrm{H}_{2} \mathrm{O}_{2}$ and carbonyl group co-activation via route II: both $\mathrm{H}_{2} \mathrm{O}_{2}$ and carbonyl on ketone are activated by Sn-based catalyst during the BV oxidation.

sites in Sn-based zeolite beta can be divided into two types: the Lewis acid Sn atom to which ketone molecule tends to coordinate, and the oxygen atom of the $\mathrm{Sn}-\mathrm{OH}$ group that interacts with $\mathrm{H}_{2} \mathrm{O}_{2}$ forming a hydrogen bond [144,145]. The effect of Lewis acidic Sn center is strong and therefore is believed to play a dominating role in the catalytic reaction of BV oxidation of ketones [142].

Tin-containing redox molecular sieves and clay catalysts, such as Sn-supported hydrotalcite composites, are environmentally advantageous catalysts not only because they can activate hydrogen peroxide but also because their heterogeneous nature enables facile catalyst recovery and recycling. Furthermore, any leached tin from these catalysts will probably in the form of inorganic tin oxides that will arouse negligible environmental threat. Tin-containing redox molecular sieves clearly demonstrate great potentials as industrial catalysts for accomplishing environmentally friendly $\mathrm{BV}$ oxidations with $\mathrm{H}_{2} \mathrm{O}_{2}$ as environmentally friendly oxidant.

\section{CONCLUSIONS AND OUTLOOK}

In this review, we first discussed very briefly the features of $\mathrm{BV}$ oxidation reaction, the catalytic mechanism, and the corresponding oxidants conventionally used, in which the catalytic BV oxidation by using $\mathrm{H}_{2} \mathrm{O}_{2}$ as oxidant should be applicable because of avoiding of waste and harmful product in traditional oxidants. The main content is then focused on the Sn-based catalysts for the BV oxidation of ketones by using cost-effective and less polluting $\mathrm{H}_{2} \mathrm{O}_{2}$ as oxidant. The catalytic performances and the catalytic mechanisms of most kinds of Sn-based catalysts reported so far were reviewed and discussed, including the homogeneous catalysts (such as Sn-based FBS), and heterogeneous catalysts (such as Sn-based zeolite catalyst, Sn-based mesoporous composites, $\mathrm{Sn}$ incorporated clay catalyst, tin-based metal oxide composites, and polymer supported Sn cata- lyst). Two types of catalytic mechanisms of Sn-based catalysts have been proposed, namely, 1) ketone carbonyl activation by the coordination to the Lewis acid Sn site of the catalyst leading to the intensified electrophilicity of carbon which facilitates the nucleophilic attack by $\mathrm{H}_{2} \mathrm{O}_{2}$ molecule; 2) both oxidant $\mathrm{H}_{2} \mathrm{O}_{2}$ and carbonyl of ketone are activated, resulting in much accelerated $\mathrm{BV}$ oxidation. In the second type of catalytic mechanism, the co-activation of $\mathrm{H}_{2} \mathrm{O}_{2}$ and carbonyl of ketone are accomplished via two different routes: in route (I), the oxidant $\mathrm{H}_{2} \mathrm{O}_{2}$ is activated by organic solvent or additive used, such as acetonitrile, to form peroxycarboxymidic intermediate, and in the meantime, the carbonyl of ketone is activated by Lewis acidic Sn site resulting in the intensified electrophilicity of the carbonyl carbon, which facilitates the nucleophilic attack by the peroxycarboxymidic intermediate formed previously; Comparatively, the route (II) is featured with the co-activation of both of $\mathrm{H}_{2} \mathrm{O}_{2}$ and ketone substrate by specific $\mathrm{Sn}$-based catalysts, in which the $\mathrm{H}_{2} \mathrm{O}_{2}$ is activated to form peroxycarboxymidic intermediate and then nucleophilically attacks the carbonyl carbon of ketone which has been activated by the coordination to Sn-based catalyst. The Sn-based catalyst in route (II) is bifunctional-Brønsted basic site at the Sn-based catalyst surface activate $\mathrm{H}_{2} \mathrm{O}_{2}$ and the coordination to $\mathrm{Sn}$ species can activate the carbonyl carbon of ketone.

Among the Sn-based BV oxidation catalysts reported, the catalytic processes of Sn cooperated FBS catalyst, Sn-based zeolite catalyst, Sn-based mesoporous composites, Sn incorporated cationic clay catalyst, such as palygorskite supported $\mathrm{Sn}(\mathrm{II})$ complexes and $\mathrm{SnCl}_{2}$ incorporated MMT, Sn-bentonite and polymer supported Sn catalyst are proposed to follow the first type of mechanism of single carbonyl of ketone activation. Differently, that of $\mathrm{Sn}$ incorporated anionic clay catalyst, such as tin oxide supported on an $\mathrm{Mg} / \mathrm{Al}$ hydrotalcite most probably follows 
the second type of oxidant $\mathrm{H}_{2} \mathrm{O}_{2}$ and carbonyl co-activation via route (I), i.e., $\mathrm{H}_{2} \mathrm{O}_{2}$ and carbonyl are activated respectively by the solvent used and the $\mathrm{Sn}$ active sites on Sn-based catalyst; comparatively, those of hydrotalcites contained variable metal composition $(\mathrm{Mg} / \mathrm{Al}, \mathrm{Mg} / \mathrm{Al} / \mathrm{Sn}$ and $\mathrm{Mg} / \mathrm{Al} / \mathrm{Zr}$ ) and the Sn-based metal oxide composites, such as $\mathrm{MgO} / \mathrm{SnO}_{2}$ also proceed according to the second type of the catalytic mechanisms but via route (II), in which both $\mathrm{H}_{2} \mathrm{O}_{2}$ and carbonyl are activated by the $\mathrm{Sn}$ active sites on $\mathrm{Sn}$-based catalyst. We expect that the above catalytic mechanism discussions and proposals will be helpful for understanding the catalytic performance of Sn-based catalysts in the BV oxidation reaction, and for searching even better catalysts as well for the practical application of the catalytic BV oxidation of ketones.

Tin-based catalysts, owing to their strong Lewis acidic site character, exhibit high catalytic performance for the catalytic BV oxidation of ketone or cyclic ketone by using cost-effective and environmentally friendly $\mathrm{H}_{2} \mathrm{O}_{2}$ as oxidant. It should be pointed out that among many kinds of catalysts, heterogeneous Sn-containing catalysts are becoming increasingly attractive due to their unique characters of simple operation, nontoxicity, easy separation, acceptable recoverability, etc. Though the overall catalytic activity of homogeneous $\mathrm{Sn}$-containing organic catalysts is comparable to that of heterogeneous catalysts, the practical applications of the former during the BV oxidation has been limited because of their toxicity and possible pollution to water and air. Comparatively, Sn-based heterogeneous catalyst is a much better option for catalyzing BV oxidation reactions.

Among various Sn-based heterogeneous catalysts, Sn-based zeolite molecular sieves, featuring the extraordinarily high conversion rates and chemoselectivities, are superior to other kinds of Sn-containing catalysts. Especially, in the $\mathrm{BV}$ oxidations of unsaturated ketone, the chemoselectivity is extraordinarily high by using Sn-based zeolite molecular sieves as catalyst with the aim product being frequently $100 \%$ ester or lactone. More attractively, after the introduction of mesopore structure into the zeolite crystals, the obtained Sn-containing mesoporous zeolite presents a substantially enhanced catalytic performance in the BV oxidations of bulky cycle ketones with large molecular weights. However, the synthesis of Sn-based zeolites is still not simple, and usually long synthetic periods and careful controls over the hierarchically porous structure are necessary. Comparatively, Sn-incorporated clay catalysts are characteristic of simple synthesis, abundance in nature and therefore much more cost-effective, which make the catalyst highly promising for the large-scale industrial applications. Unfortunately, compared to other Sn-based catalysts, the product yields of BV oxidations by employing Sn-incorporated clays, such as Sn-palygorskite as catalyst, is relatively low, and much longer reaction time periods will be needed. In addition, $\mathrm{Sn}$-incorporated clay catalysts, such as Sn-hydrotalcite, are not active enough for the BV oxidation of aliphatic and acyclic ketones.

In spite of the significant progresses made in the past decades, the overall performance of Sn-containing catalysts in BV oxidation reactions, when employed in the practical applications, is still not as perfect as expected, and therefore there is still rooms for improvement. First, the recyclability of Sn-based heterogeneous catalyst should be substantially enhanced by developing novel catalysts or modifying the reported ones, that is to say, the problems of metal active species falling off and activity loss should be resolved before industrial applications to guarantee the recycled use and long enough catalytic lifetime of the catalysts. Secondly, Sn-based catalysts of crystalline architectures are expected to possess tunable and large enough pore structures for the free accesses of bulky ketone or cycle ketone molecules to the active catalytic sites in the inner framework of the catalysts. Additionally, further detailed fundamental investigations should be engaged in understanding the origin and nature of the catalytic activity in the BV oxidations on atomic levels, which are not only dependent on the metal ions incorporated, but also on the atomic environments around the metal ions. The differences in catalytic activity between external and internal active sites of the Sn-based catalysts are also fundamentally interesting. Finally but even more challengingly, the development of novel catalysts, including Sn-based heterogeneous catalysts for catalyzing the organic co-solvent-free BV oxidation reactions using oxygen or air as oxidant, will become a great breakthrough in the field. The success in finding this kind of novel catalysts will further remarkably enhance the atom economy of the reaction, and reduce the reaction cost and potential harms to environments, which may greatly promote the more extensive industrializations of various BV oxidation reactions from fine chemical engineering to the syntheses of general chemicals, and finally benefit the sustained development of the industry production of useful chemicals.

Received 14 June 2016; accepted 12 July 2016; published online 18 August 2016

1 Baeyer A, Villiger V. Einwirkung des Caro'schen Reagens auf Ke- 
tone. Ber Dtsch Chem Ges, 1899, 32: 3625-3633

2 Fiorentini F, Geier M, Binda C, et al. Biocatalytic characterization of human FMO5: unearthing Baeyer-Villiger reactions in humans. ACS Chem Biol, 2016, 11: 1039-1048

3 Leisch H, Morley K, Lau PCK. Baeyer-Villiger monooxygenases: more than just green chemistry. Chem Rev, 2011, 111: 4165-4222

4 Zhou L, Liu X, Ji J, et al. Enantioselective Baeyer-Villiger oxidation: desymmetrization of meso cyclic ketones and kinetic resolution of racemic 2-arylcyclohexanones. J Am Chem Soc, 2012, 134: 17023-17026

5 Romney DK, Colvin SM, Miller SJ. Catalyst control over regio- and enantioselectivity in Baeyer-Villiger oxidations of functionalized ketones. J Am Chem Soc, 2014, 136: 14019-14022

6 Flourat AL, Peru AAM, Teixeira ARS, et al. Chemo-enzymatic synthesis of key intermediates (S)- $\gamma$-hydroxymethyl- $\alpha, \beta$-butenolide and (S)- $\gamma$-hydroxymethyl- $\gamma$-butyrolactone via lipase-mediated Baeyer-Villiger oxidation of levoglucosenone. Green Chem, 2015, 17: 404-412

7 Strukul G. Chemistry: how green was my ester. Nature, 2001, 412: 388-389

8 Michelin RA, Sgarbossa P, Scarso A, et al. The Baeyer-Villiger oxidation of ketones: a paradigm for the role of soft Lewis acidity in homogeneous catalysis. Coordin Chem Rev, 2010, 254: 646-660

9 Sicard R, Chen LS, Marsaioli AJ, et al. A fluorescence-based assay for Baeyer-Villiger monooxygenases, hydroxylases and lactonases. Adv Synth Catal, 2005, 347: 1041-1050

10 Cooper MS, Heaney H, Newbold AJ, et al. Oxidation reactions using urea-hydrogen peroxide; a safe alternative to anhydrous hydrogen peroxide. Synlett, 1990, 1990: 533-535

11 Yoshida A, Yoshimura M, Uehara K, et al. Formation of S-shaped disilicoicosatungstate and efficient Baeyer-Villiger oxidation with hydrogen peroxide. Angew Chem Int Ed, 2006, 45: 1956-1960

12 Yang Z, Niu L, Jia X, et al. Preparation of silica-supported sulfate and its application as a stable and highly active solid acid catalyst. Catal Commun, 2011, 12: 798-802

13 Ma Q, Xing W, Xu J, et al. Baeyer-Villiger oxidation of cyclic ketones with aqueous hydrogen peroxide catalyzed by transition metal oxides. Catal Commun, 2014, 53: 5-8

14 Xing W, Ma Q, Peng X. Silica/A153- $\mathrm{SO}_{3} \mathrm{H}$ : an efficient catalyst for the Baeyer-Villiger oxidation of cyclic ketones with hydrogen peroxide. Comptes Rendus Chimie, 2015, 18: 581-585

15 ten Brink GJ, Vis JM, Arends IWCE, et al. Selenium-catalyzed oxidations with aqueous hydrogen peroxide. 2. Baeyer-Villiger reactions in homogeneous solution. J Org Chem, 2001, 66: 2429-2433

16 Alegria ECBA, Martins LMDRS, Kirillova MV, et al. Baeyer-Villiger oxidation of ketones catalysed by rhenium complexes bearing N- or oxo-ligands. Appl Catal A-Gen, 2012, 443-444: 27-32

17 Watanabe $\mathrm{A}$, Uchida $\mathrm{T}$, Ito $\mathrm{K}$, et al. Highly enantioselective Baeyer-Villiger oxidation using $\mathrm{Zr}$ (salen) complex as catalyst. Tetrahedron Lett, 2002, 43: 4481-4485

18 Jin P, Zhu L, Wei D, et al. A DFT study on the mechanisms of tungsten-catalyzed Baeyer-Villiger reaction using hydrogen peroxide as oxidant. Comp Theor Chem, 2011, 966: 207-212

19 Petersen KS, Stoltz BM. Palladium-catalyzed, asymmetric Baeyer-Villiger oxidation of prochiral cyclobutanones with PHOX ligands. Tetrahedron, 2011, 67: 4352-4357

20 Figg TM, Webb JR, Cundari TR, et al. Carbon-oxygen bond formation via organometallic Baeyer-Villiger transformations: a computational study on the impact of metal identity. J Am Chem Soc, 2012, 134: 2332-2339

21 Duarte TAG, Estrada AC, Simões MMQ, et al. Homogeneous catalytic oxidation of styrene and styrene derivatives with hydrogen peroxide in the presence of transition metal-substituted polyoxotungstates. Catal Sci Technol, 2015, 5: 351-363

22 Sinhamahapatra A, Sinha A, Pahari SK, et al. Room temperature Baeyer-Villiger oxidation using molecular oxygen over mesoporous zirconium phosphate. Catal Sci Technol, 2012, 2: 2375-2382

23 Zhou Y, Huang R, Ding F, et al. Sulfonic acid-functionalized $\alpha$-zirconium phosphate single-layer nanosheets as a strong solid acid for heterogeneous catalysis applications. ACS Appl Mater Interf, 2014, 6: 7417-7425

24 Uyanik M, Nakashima D, Ishihara K. Baeyer-Villiger oxidation and oxidative cascade reactions with aqueous hydrogen peroxide catalyzed by lipophilic $\mathrm{Li}\left[\mathrm{B}\left(\mathrm{C}_{6} \mathrm{~F}_{5}\right)_{4}\right]$ and $\mathrm{Ca}\left[\mathrm{B}\left(\mathrm{C}_{6} \mathrm{~F}_{5}\right)_{4}\right]_{2}$. Angew Chem Int Ed, 2012, 51: 9093-9096

25 Uyanik M, Ishihara K. Baeyer-Villiger oxidation using hydrogen peroxide. ACS Catal, 2013, 3: 513-520

26 ten Brink GJ, Arends IWCE, Sheldon RA. The Baeyer-Villiger reaction: new developments toward greener procedures. Chem Rev, 2004, 104: 4105-4124

27 Renz M, Meunier B. 100 Years of Baeyer-Villiger oxidations. Eur J Org Chem, 1999, 14: 737-750

28 Jiménez-Sanchidrián C, Ruiz JR. The Baeyer-Villiger reaction on heterogeneous catalysts. Tetrahedron, 2008, 64: 2011-2026

29 Horvath IT, Rabai J. Facile catalyst separation without water fluorous biphase hydroformylation of olefins. Science, 1994, 266: $72-75$

30 Mikami K, Islam MN, Yamanaka M, et al. Nanoflow system for perfect regiocontrol in the Baeyer-Villiger oxidation by aqueous hydrogen peroxide using lowest concentration of a fluorous lanthanide catalyst. Tetrahedron Lett, 2004, 45: 3681-3683

31 Hao X, Yamazaki O, Yoshida A, et al. Green Baeyer-Villiger oxidation with hydrogen peroxide: $\mathrm{Sn}\left[\mathrm{N}\left(\mathrm{SO}_{2} \mathrm{C}_{8} \mathrm{~F}_{17}\right)_{2}\right]_{4}$ as a highly selective Lewis acid catalyst in a fluorous biphase system. Green Chem, 2003, 5: 524-528

32 Hao X, Yamazaki O, Yoshida A, et al. Tin(IV) bis(perfluoroalkanesulfonyl)amide complex as a highly selective Lewis acid catalyst for Baeyer-Villiger oxidation using hydrogen peroxide in a fluorous recyclable phase. Tetrahedron Lett, 2003, 44: 4977-4980

33 Li Y, Yu J. New stories of zeolite structures: their descriptions, determinations, predictions, and evaluations. Chem Rev, 2014, 114 7268-7316

34 Roth WJ, Nachtigall P, Morris RE, et al. Two-dimensional zeolites: current status and perspectives. Chem Rev, 2014, 114: 4807-4837

35 Valtchev V, Tosheva L. Porous nanosized particles: preparation, properties, and applications. Chem Rev, 2013, 113: 6734-6760

36 Camblor MA, Corma A, Martínez A, et al. Synthesis of a titaniumsilicoaluminate isomorphous to zeolite beta and its application as a catalyst for the selective oxidation of large organic molecules. J Chem Soc Chem Commun, 1992, 0: 589-590

37 Sen T, Chatterjee M, Sivasanker S. Novel large-pore vanadium alumino- and boro-silicates with BEA structure. J Chem Soc Chem Commun, 1995, 207-208

38 Panchgalle SP, Kalkote UR, Niphadkar PS, et al. Sn- $\beta$ molecular sieve catalysed Baeyer-Villiger oxidation in ionic liquid at room temperature. Green Chem, 2004, 6: 308-309

39 Yang D, Wang X, Shi B, et al. Synthesis of ZSM-5/EU-1 composite zeolite and its application in conversion of methanol to xylene. J Inorg Mater, 2014, 29: 357-363

40 Corma A, Nemeth LT, Renz M, et al. Sn-zeolite beta as a heterogeneous chemoselective catalyst for Baeyer-Villiger oxidations. Nature, 2001, 412: 423-425

41 Corma A. One-pot synthesis of phenols from aromatic aldehydes 
by Baeyer-Villiger oxidation with $\mathrm{H}_{2} \mathrm{O}_{2}$ using water-tolerant Lewis acids in molecular sieves. J Catal, 2004, 221: 67-76

42 Bare SR, Kelly SD, Sinkler W, et al. Uniform catalytic site in Sn- $\beta$ zeolite determined using X-ray absorption fine structure. J Am Chem Soc, 2005, 127: 12924-12932

43 Renz M, Blasco T, Corma A, et al. Selective and shape-selective Baeyer-Villiger oxidations of aromatic aldehydes and cyclic ketones with Sn-beta zeolites and $\mathrm{H}_{2} \mathrm{O}_{2}$. Chem Eur J, 2002, 8: 4708-4717

44 Li P, Liu G, Wu H, et al. Postsynthesis and selective oxidation properties of nanosized Sn-beta zeolite. J Phys Chem C, 2011, 115: 3663-3670

45 Kang Z, Zhang X, Liu H, et al. A rapid synthesis route for Sn-beta zeolites by steam-assisted conversion and their catalytic performance in Baeyer-Villiger oxidation. Chem Eng J, 2013, 218: 425-432

46 Luo HY, Bui L, Gunther WR, et al. Synthesis and catalytic activity of Sn-MFI nanosheets for the Baeyer-Villiger oxidation of cyclic ketones. ACS Catal, 2012, 2: 2695-2699

47 Jin J, Ye X, Li Y, et al. Synthesis of mesoporous Beta and Sn-Beta zeolites and their catalytic performances. Dalton Trans, 2014, 43: 8196-8204

48 Ouyang X, Hwang SJ, Xie D, et al. Heteroatom-substituted delaminated zeolites as solid Lewis acid catalysts. ACS Catal, 2015, 5: 3108-3119

49 Liu G, Jiang JG, Yang B, et al. Hydrothermal synthesis of MWW-type stannosilicate and its post-structural transformation to MCM-56 analogue. Micropor Mesopor Mater, 2013, 165: $210-218$

50 Dutta B, Jana S, Bhunia S, et al. Heterogeneous Baeyer-Villiger oxidation of cyclic ketones using tert-BuOOH as oxidant. Appl Catal A-Gen, 2010, 382: 90-98

51 Davis ME. Ordered porous materials for emerging applications. Nature, 2002, 417: 813-821

52 Shi J. On the synergetic catalytic effect in heterogeneous nanocomposite catalysts. Chem Rev, 2013, 113: 2139-2181

53 Christianson JR, Caratzoulas S, Vlachos DG. Computational insight into the effect of Sn-Beta Na exchange and solvent on glucose isomerization and epimerization. ACS Catal, 2015, 5: 5256-5263

54 Moliner M. State of the art of Lewis acid-containing zeolites: lessons from fine chemistry to new biomass transformation processes. Dalton Trans, 2014, 43: 4197-4208

55 Pérez-Ramírez J, Christensen CH, Egeblad K, et al. Hierarchical zeolites: enhanced utilisation of microporous crystals in catalysis by advances in materials design. Chem Soc Rev, 2008, 37: 2530-2542

56 Ding K, Corma A, Maciá-Agulló JA, et al. Constructing hierarchical porous zeolites via kinetic regulation. J Am Chem Soc, 2015, 137: 11238-11241

57 Ren L, Guo Q, Kumar P, et al. Self-pillared, single-unit-cell Sn-MFI zeolite nanosheets and their use for glucose and lactose isomerization. Angew Chem Int Ed, 2015, 54: 10848-10851

58 Kresge CT, Leonowicz ME, Roth WJ, et al. Ordered mesoporous molecular sieves synthesized by a liquid-crystal template mechanism. Nature, 1992, 359: 710-712

59 Corma A, Navarro MÃT, Nemeth L, et al. Sn-MCM-41-a heterogeneous selective catalyst for the Baeyer-Villiger oxidation with hydrogen peroxide. Chem Commun, 2001, 2190-2191

60 Corma A, Navarro MT, Renz M. Lewis acidic Sn(IV) centers-grafted onto MCM-41-as catalytic sites for the Baeyer-Villiger oxidation with hydrogen peroxide. J Catal, 2003, 219: 242-246

61 Li G, Zhong L, Yuan X, et al. Preparation, characterization and catalytic properties of Sn-containing MCM-41. J Inorg Mater, 2010,
25: 1041-1046

62 Li G, Zhong L, Yuan X, Wu J, Luo H. Baeyer-Villiger oxidation of cyclohexanone over Sn doping MCM-41 molecular sieve. Chem React Eng Technol, 2010, 2: 162-166

63 Chen N, Jiang Y, Cheng W, et al. Synthesis of submicrometer-sized Sn-MCM-41 particles and their catalytic performance in BaeyerVilliger oxidation. Chem Res Chin Univ, 2015, 31: 138-143

64 Chen T, Wang B, Li Y, et al. Hydrothermal synthesis of tin containing mesoporous silicas and their catalytic performance over Baeyer-Villiger oxidation of cyclohexanone to $\varepsilon$-caprolactone: comparison of Sn/MCM-41 and Sn/SBA-15. J Porous Mater, 2015, 22: 949-957

65 Nekoksová I, Zilková N, Čejka J. Oxidation of adamantanone and norcamphor over tin containing mesoporous molecular sieves. Stud Surf Sci Catal, 2005, 158: 1589-1596

66 Corma A, Renz M. Experimental evidence for a dual site mechanism in Sn-Beta and Sn-MCM-41 catalysts for the Baeyer-Villiger oxidation. Collect Czech Chem Commun, 2005, 70: 1727-1736

67 Böttcher S, Hoffmann C, Räuchle K, et al. Pore structure and surface acidity effects of ordered mesoporous supports on enantioselective hydrogenation of ethyl pyruvate. ChemCatChem, 2011, 3: 741-748

68 Zhao Y, Zhang Y, Chen J, et al. SBA-16-supported cobalt catalyst with high activity and stability for fischer-tropsch synthesis. ChemCatChem, 2012, 4: 265-272

69 Azizi SN, Ghasemi S, Yazdani-Sheldarrei H. Synthesis of mesoporous silica (SBA-16) nanoparticles using silica extracted from stem cane ash and its application in electrocatalytic oxidation of methanol. Int J Hydrogen Energy, 2013, 38: 12774-12785

70 Maheswari R, Pachamuthu MP, Ramanathan A, et al. Synthesis, characterization, and epoxidation activity of tungsten-incorporated SBA-16 (W-SBA-16). Ind Eng Chem Res, 2014, 53: 18833-18839

71 Jiang N, Koo JB, Han SC, et al. Lewis-type catalytic activity of direct incorporated $\mathrm{Zr}$ - and Sn-SBA-16 catalysts. Res Chem Intermed, 2008, 34: 507-517

72 Jeong EY, Ansari MB, Mo YH, et al. Removal of $\mathrm{Cu}(\mathrm{II})$ from water by tetrakis(4-carboxyphenyl) porphyrin-functionalized mesoporous silica. J Hazard Mater, 2011, 185: 1311-1317

73 de F. Castro KAD, Simões MMQ, da Graça P.M.S. Neves M, et al. Synthesis of new metalloporphyrin derivatives from [5,10,15,20-tetrakis (pentafluorophenyl)porphyrin] and 4-mercaptobenzoic acid for homogeneous and heterogeneous catalysis. Appl Catal A-Gen, 2015, 503: 9-19

74 Liu W, Groves JT. Manganese catalyzed C-H halogenation. Acc Chem Res, 2015, 48: 1727-1735

75 Ottenbacher RV, Talsi EP, Bryliakov KP. Mechanism of selective $\mathrm{C}-\mathrm{H}$ hydroxylation mediated by manganese aminopyridine enzyme models. ACS Catal, 2015, 5: 39-44

76 Fu L, Chen Y, Liu Z. Cobalt catalysts embedded in N-doped carbon derived from cobalt porphyrin via a one-pot method for ethylbenzene oxidation. J Mol Catalysis A-Chem, 2015, 408: 91-97

77 Jeong EY, Ansari MB, Park SE. Aerobic Baeyer-Villiger oxidation of cyclic ketones over metalloporphyrins bridged periodic mesoporous organosilica. ACS Catal, 2011, 1: 855-863

78 Pan L, Liu J, He Q, et al. MSN-mediated sequential vascular-to-cell nuclear-targeted drug delivery for efficient tumor regression. Adv Mater, 2014, 26: 6742-6748

79 Liu J, Bu J, Bu W, et al. Real-time in vivo quantitative monitoring of drug release by dual-mode magnetic resonance and upconverted luminescence imaging. Angew Chem Int Ed, 2014, 53: 4551-4555

80 Liu J, Liu Y, Bu W, et al. Ultrasensitive nanosensors based on 
upconversion nanoparticles for selective hypoxia imaging in vivo upon near-infrared excitation. J Am Chem Soc, 2014, 136: 9701-9709

81 Wang Y, Yokoi T, Otomo R, et al. Synthesis of Sn-containing mesoporous silica nanospheres as efficient catalyst for Baeyer-Villiger oxidation. Appl Catal A-Gen, 2015, 490: 93-100

82 Shahidi D, Roy R, Azzouz A. Advances in catalytic oxidation of organic pollutants - prospects for thorough mineralization by natural clay catalysts. Appl Catal B-Environ, 2015, 174-175: 277-292

83 An N, Zhou CH, Zhuang XY, et al. Immobilization of enzymes on clay minerals for biocatalysts and biosensors. Appl Clay Sci, 2015, 114: 283-296

84 Lei Z, Zhang Q, Luo J, et al. Baeyer-Villiger oxidation of ketones with hydrogen peroxide catalyzed by Sn-palygorskite. Tetrahedron Lett, 2005, 46: 3505-3508

85 Lei Z, Zhang Q, Wang R, et al. Clean and selective Baeyer-Villiger oxidation of ketones with hydrogen peroxide catalyzed by Sn-palygorskite. J Organomet Chem, 2006, 691: 5767-5773

86 Shahidi D, Moheb A, Abbas R, et al. Total mineralization of sulfamethoxazole and aromatic pollutants through $\mathrm{Fe}^{2+}$-montmorillonite catalyzed ozonation. J Hazard Mater, 2015, 298: 338-350

87 Atta AM, Al-Lohedan HA, ALOthman ZA, et al. Characterization of reactive amphiphilic montmorillonite nanogels and its application for removal of toxic cationic dye and heavy metals water pollutants. J Industrial Eng Chem, 2015, 31: 374-384

88 Tan X, Lu H, Wang J, et al. Synthesis of iron oxides intercalated montmorillonite and a-zirconium phosphate particles and their applications in polystyrene composites. J Appl Polym Sci, 2015, 132: $42737-42744$

89 Lei Z, Ma G, Jia C. Montmorillonite (MMT) supported tin (II) chloride: an efficient and recyclable heterogeneous catalyst for clean and selective Baeyer-Villiger oxidation with hydrogen peroxide. Catal Commun, 2007, 8: 305-309

90 Ma Q, Li L, Cao Y, et al. Sn-bentonite-induced Baeyer-Villiger oxidation of 2-heptylcyclopentanone to $\delta$-dodecalactone with aqueous hydrogen peroxide. Res Chem Intermed, 2015, 41: 2249-2256

91 Guo X, Zhang F, Evans DG, et al. Layered double hydroxide films: synthesis, properties and applications. Chem Commun, 2010, 46: 5197

92 Carillo A, Griego D. Hydroxides: Synthesis, Types and Applications. New York: Nova Sciences Publishers, 2011

93 I. Fernandes C, D. Nunes C, D. Vaz P. Clays in organic synthesispreparation and catalytic applications. Curr Org Synth, 2012, 9: 670-694

94 Carja G, Birsanu M, Okada K, et al. Composite plasmonic gold/layered double hydroxides and derived mixed oxides as novel photocatalysts for hydrogen generation under solar irradiation. J Mater Chem A, 2013, 1: 9092-9098

95 Debecker DP, Gaigneaux EM, Busca G. Exploring, tuning, and exploiting the basicity of hydrotalcites for applications in heterogeneous catalysis. Chem Eur J, 2009, 15: 3920-3935

96 Liu P, Derchi M, Hensen EJM. Promotional effect of transition metal doping on the basicity and activity of calcined hydrotalcite catalysts for glycerol carbonate synthesis. Appl Catal B-Environ, 2014, 144: 135-143

97 Pillai U. Sn-exchanged hydrotalcites as catalysts for clean and selective Baeyer-Villiger oxidation of ketones using hydrogen peroxide. J Mol Catalysis A-Chem, 2003, 191: 93-100

98 Yamaguchi K, Mori K, Mizugaki T, et al. Epoxidation of $\alpha, \beta$-unsaturated ketones using hydrogen peroxide in the presence of basic hydrotalcite catalysts. J Org Chem, 2000, 65: 6897-6903

99 Pillai UR, Sahle-Demessie E, Varma RS. Microwave-expedited olefin epoxidation over hydrotalcites using hydrogen peroxide and acetonitrile. Tetrahedron Lett, 2002, 43: 2909-2911

100 Smith M, March J. March's Advanced Organic Chemistry: Reactions, Mechanisms and Structure, 5th Edition, New York: Wiley, 2001, Chapter 18, 1417

101 Jimenezsanchidrian C, Hidalgo J, Llamas R, et al. Baeyer-Villiger oxidation of cyclohexanone with hydrogen peroxide/benzonitrile over hydrotalcites as catalysts. Appl Catal A-Gen, 2006, 312: 86-94

102 Prihod'ko R, Sychev M, Kolomitsyn I, et al. Layered double hydroxides as catalysts for aromatic nitrile hydrolysis. Micropor Mesopor Mater, 2002, 56: 241-255

103 Yang ZQ, Park SE. Baeyer-Villiger reaction of adamantanone over Sn-containing hydrotalcite-like catalysts. Solid State Phenom, 2007, 119: 163-166

104 Hara T, Hatakeyama M, Kim A, et al. Preparation of clay-supported Sn catalysts and application to Baeyer-Villiger oxidation. Green Chem, 2012, 14: 771-777

105 Thornburg NE, Thompson AB, Notestein JM. Periodic trends in highly dispersed groups IV and V supported metal oxide catalysts for alkene epoxidation with $\mathrm{H}_{2} \mathrm{O}_{2}$. ACS Catal, 2015, 5: 5077-5088

106 Belelli PG, Ferretti CA, Apesteguía CR, et al. Glycerolysis of methyl oleate on $\mathrm{MgO}$ : experimental and theoretical study of the reaction selectivity. J Catal, 2015, 323: 132-144

107 Severin KG, Abdel-Fattah TM. Supramolecular assembly of mesostructured tin oxide. Chem Commun, 1998, 1471-1472

108 Yang P, Zhao D, Margolese DI, et al. Block copolymer templating syntheses of mesoporous metal oxides with large ordering lengths and semicrystalline framework. Chem Mater, 1999, 11: 2813-2826

109 Wong MS, Ying JY. Amphiphilic templating of mesostructured zirconium oxide. Chem Mater, 1998, 10: 2067-2077

110 Shiraishi Y, Saito N, Hirai T. Adsorption-driven photocatalytic activity of mesoporous titanium dioxide. J Am Chem Soc, 2005, 127: $12820-12822$

111 Kuemmel M, Grosso D, Boissière C, et al. Thermally stable nanocrystalline $\gamma$-alumina layers with highly ordered 3D mesoporosity. Angew Chem Int Ed, 2005, 44: 4589-4592

112 Nakajima K, Fukui T, Kato H, et al. Structure and acid catalysis of mesoporous $\mathrm{Nb}_{2} \mathrm{O}_{5} \cdot n \mathrm{H}_{2} \mathrm{O}$. Chem Mater, 2010, 22: 3332-3339

113 Noda Y, Lee B, Domen K, et al. Synthesis of crystallized mesoporous tantalum oxide and its photocatalytic activity for overall water splitting under ultraviolet light irradiation. Chem Mater, 2008, 20: $5361-5367$

114 Katou T, Lee B, Lu D, et al. Crystallization of an ordered mesoporous $\mathrm{Nb}-\mathrm{Ta}$ oxide. Angew Chem Int Ed, 2003, 42: 2382-2385

115 de la Torre O, Renz M, Corma A. Biomass to chemicals: rearrangement of $\beta$-pinene epoxide into myrtanal with well-defined singlesite substituted molecular sieves as reusable solid Lewis-acid catalysts. Appl Catal A-Gen, 2010, 380: 165-171

116 Kondo JN, Uchida M, Nakajima K, et al. Synthesis, mesostructure, and photocatalysis of a highly ordered and thermally stable mesoporous $\mathrm{Mg}$ and Ta mixed oxide. Chem Mater, 2004, 16: 4304-4310

117 Tagusagawa C, Takagaki A, Iguchi A, et al. Highly active mesoporous $\mathrm{Nb}-\mathrm{W}$ oxide solid-acid catalyst. Angew Chem Int Ed, 2010, 49: $1128-1132$

118 Jin X, Oishi T, Yamaguchi K, et al. Heterogeneously catalyzed efficient hydration of alkynes to ketones by tin-tungsten mixed oxides. Chem Eur J, 2011, 17: 1261-1267

119 Shiju NR, AnilKumar M, Hoelderich WF, et al. Tungstated zirconia catalysts for liquid-phase Beckmann rearrangement of cyclohexanone oxime: structure-activity relationship. J Phys Chem C, 2009, 113: 7735-7742

120 Ramos-Delgado NA, Gracia-Pinilla MA, Maya-Treviño L, et al. So- 
lar photocatalytic activity of $\mathrm{TiO}_{2}$ modified with $\mathrm{WO}_{3}$ on the degradation of an organophosphorus pesticide. J Hazard Mater, 2013, 263: 36-44

121 Muñoz-Batista MJ, Kubacka A, Rachwalik R, et al. Green photooxidation of styrene over W-Ti composite catalysts. J Catal, 2014, 309: 428-438

122 Rao Y, Kang J, Antonelli D. 1-Hexene isomerization over sulfated mesoporous Ta oxide: the effects of active site and confinement. J Am Chem Soc, 2008, 130: 394-395

123 Ruiz JR, Jiménez-Sanchidrián C, Llamas R. Hydrotalcites as catalysts for the Baeyer-Villiger oxidation of cyclic ketones with hydrogen peroxide/benzonitrile. Tetrahedron, 2006, 62: 11697-11703

124 Llamas R, Jiménez-Sanchidrián C, Ruiz JR. Metal hydroxides as catalysts for the Baeyer-Villiger oxidation of cyclohexanone with hydrogen peroxide. React Kinet Catal Lett, 2007, 90: 309-313

125 Jiménez-Sanchidrián C, Ruiz JR. Tin-containing hydrotalcite-like compounds as catalysts for the Meerwein-Ponndorf-Verley reaction. Appl Catal A-Gen, 2014, 469: 367-372

126 Li J, Huang L, Dai W, Fan K. Baeyer-Villiger oxidation of cyclohexanone to caprolactone over highly efficient $\mathrm{MgO} / \mathrm{SnO}_{2}$ catalyst using $\mathrm{H}_{2} \mathrm{O}_{2}$ as oxidant. Acta Chimica Sinica, 2008, 66: 5-9

127 Yang Z, Niu L, Ma Z, et al. Fabrication of highly active Sn/W mixed transition-metal oxides as solid acid catalysts. Trans Met Chem, 2011, 36: 269-274

128 Yang $\mathrm{Z}$, Chen L, Hong W, et al. Baeyer-Villiger oxidation and acetalization of cyclic ketones on $\mathrm{SO}_{4}{ }^{2-} / \mathrm{SnO}_{2}-\mathrm{Fe}_{2} \mathrm{O}_{3}$ solid acid catalysts. Acta Phys-Chim Sin, 2012, 28: 2148-2154

129 Zhang G, Ren $\mathrm{X}$, Zhang $\mathrm{H}$, et al. $\mathrm{MgO} / \mathrm{SnO}_{2} / \mathrm{WO}_{3}$ as catalysts for synthesis of $\varepsilon$-caprolactone over oxidation of cyclohexanone with peracetic acid. Catal Commun, 2015, 58: 59-63

130 Ma Y, Liang Z, Feng S, et al. Baeyer-Villiger oxidation of cyclohexanone by molecular oxygen with $\mathrm{Fe}-\mathrm{Sn}-\mathrm{O}$ mixed oxides as catalysts. Appl Organometal Chem, 2015, 29: 450-455

131 Nenajdenko VG, Muzalevskiy VM, Shastin AV. Polyfluorinated ethanes as versatile fluorinated C2-building blocks for organic synthesis. Chem Rev, 2015, 115: 973-1050

132 Merrifield B. Solid phase synthesis. Science, 1986, 232: 341-347

133 Marchetti P, Jimenez Solomon MF, Szekely G, et al. Molecular separation with organic solvent nanofiltration: a critical review. Chem Rev, 2014, 114: 10735-10806

134 Zhang Q, Wen S, Lei Z. Heterogeneous Baeyer-Villiger oxidation of ketones using hydrogen peroxide as oxidant catalyzed by aminomethyl polystyrene resin-supported tin complex. React Funct Polym, 2006, 66: 1278-1283

135 Li CL, Yang ZW, Wu S, et al. Chloromethyl polystyrene supported dendritic Sn complexes, preparation and catalytic Baeyer-Villiger oxidation. React Funct Polym, 2007, 67: 53-59

136 Li C, Wang J, Yang Z, et al. Baeyer-Villiger oxidation of ketones with hydrogen peroxide catalyzed by cellulose-supported dendritic Sn complexes. Catal Commun, 2007, 8: 1202-1208

137 Li C, Lei Z, Ma H, et al. Baeyer-Villiger oxidation of ketones with hydrogen peroxide catalyzed by chitosan-supported dendritic Sn complexes. J Dispersion Sci Tech, 2012, 33: 983-989

138 Subbiah A, Pyle D, Rowland A, et al. A family of microporous materials formed by $\mathrm{Sn}(\mathrm{IV})$ phosphonate nanoparticles. J Am Chem Soc, 2005, 127: 10826-10827

139 Huang J, Subbiah A, Pyle D, et al. Globular porous nanoparticle tin(IV) phenylphosphonates and mixed methyl phenylphosphonates. Chem Mater, 2006, 18: 5213-5222

140 Kirumakki S, Samarajeewa S, Harwell R, et al. Sn(iv) phosphonates as catalysts in solvent-free Baeyer-Villiger oxidations using $\mathrm{H}_{2} \mathrm{O}_{2}$. Chem Commun, 2008, 5556

141 Sever RR, Root TW. Computational study of tin-catalyzed Baeyer-Villiger reaction pathways using hydrogen peroxide as oxidant. J Phys Chem B, 2003, 107: 10848-10862

142 Sever RR, Root TW. Comparison of epoxidation and Baeyer-Villiger reaction pathways for $\mathrm{Ti}(\mathrm{IV})-\mathrm{H}_{2} \mathrm{O}_{2}$ and $\mathrm{Sn}(\mathrm{IV})-\mathrm{H}_{2} \mathrm{O}_{2}$. J Phys Chem B, 2003, 107: 10521-10530

143 Neimann K, Neumann R. Electrophilic activation of hydrogen peroxide: selective oxidation reactions in perfluorinated alcohol solvents. Org Lett, 2000, 2: 2861-2863

144 Boronat M, Concepcion P, Corma A, et al. Determination of the catalytically active oxidation Lewis acid sites in Sn-beta zeolites, and their optimisation by the combination of theoretical and experimental studies. J Catal, 2005, 234: 111-118

145 Boronat M, Corma A, Renz M, et al. A multisite molecular mechanism for Baeyer-Villiger oxidations on solid catalysts using environmentally friendly $\mathrm{H}_{2} \mathrm{O}_{2}$ as oxidant. Chem Eur J, 2005, 11: 6905-6915

Acknowledgments This work was supported by the National Key Basic Research Program of China (2013CB933200), and the National Natural Science Foundation of Shanghai (16ZR1440600).

Author contributions Shi J conceived the study. Cui X and Shi J wrote the manuscript. Both authors discussed the manuscripts structure, arguments and conclusions.

Conflict of interest The authors declare that they have no conflict of interest. 


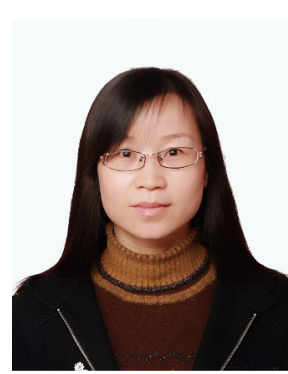

Xiangzhi Cui is an associate professor at Shanghai Institute of Ceramics, Chinese Academy of Sciences (SICCAS). She received her $\mathrm{PhD}$ degree in 2009 and has been working at the institute since then. Her main research interest includes the structural design and synthesis of mesostructured nanocomposites, and the catalytic performances of the materials for applications in fuel cells and environmental protection. She has published over 50 scientific papers which have been cited more than 1000 times by other scientists with an H-index of 17 (2016).

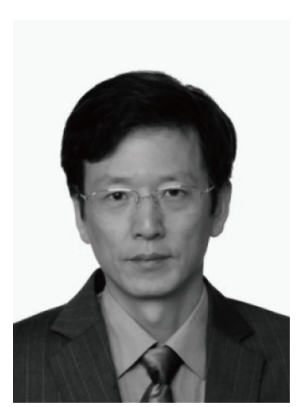

Jianlin Shi received his PhD degree from SICCAS in 1989 and currently is a professor at SICCAS. He had once worked on the processing science of advanced ceramics, solid state sintering theory of advanced ceramics, and high temperature reliability of structural ceramics from 1983 to 1998. Presently his main research interest includes the structural design and synthesis of mesoporous materials and mesostructured nanocomposites, and the catalytic and biomedical performances of the materials for applications in environmental protection and nanomedicine. He has published over 400 scientific papers which have been cited more than 17,600 times by other scientists with an H-index of 69 (2016).

\section{Sn基Baeyer-Villigery氧化反应催化剂}

崔香枝, 施剑林*

摘要 Baeyer-Villiger (BV) 反应是有机化学合成中的一个重要反应. 特别是催化型的BV反应不仅能够简化反应过程还能够降低反应物的消 耗量和减少副产物的生成量, 因此更加具有实际应用价值. 其中最为有利的催化型 $B V 反$ 应是使用低成本、环境友好的过氧化氢 $\left(\mathrm{H}_{2} \mathrm{O}_{2}\right)$ 作 为氧化剂, 来取代传统的氧化剂过酸. 本综述首先简要阐述了以 $\mathrm{H}_{2} \mathrm{O}_{2}$ 为氧化剂的 $\mathrm{BV}$ 氧化反应的特点以及传统使用的氧化剂类型, 然后重 点综述了 $\mathrm{Sn}$ 基催化剂材料在以 $\mathrm{H}_{2} \mathrm{O}_{2}$ 为氧化剂的催化型 $\mathrm{BV}$ 反应中的催化性能以及相应的催化机理, 具体包含了 $\mathrm{Sn}$ 基均相催化剂材料 (例如 $S n$ 基含氟双相体系催化剂), $S n$ 基异相催化剂材料 (例如 $S n$ 基沸石, $S n$ 基介孔复合物, $S n$ 基粘土, $S n$ 基金属氧化物, 以及 $S n$ 基聚合物催化剂). 最后, 对以 $\mathrm{H}_{2} \mathrm{O}_{2}$ 为氧化剂的 $\mathrm{BV}$ 反应的 $\mathrm{Sn}$ 基催化剂的实际应用进行了评论和展望, 讨论了它们在提高BV氧化反应催化活性方面可能的改 进和发展的方向. 